\title{
Role of Glutathione in Buffering Excess Intracellular Copper in Streptococcus pyogenes
}

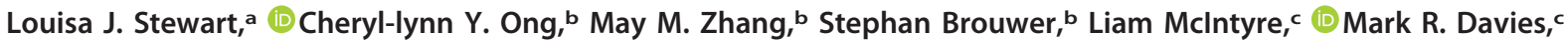 \\ (D) Mark J. Walker, (D) Alastair G. McEwan, ${ }^{\text {b }}$ (D) Kevin J. Waldron, d (D) Karrera Y. Djoko ${ }^{a}$ \\ aDepartment of Biosciences, Durham University, Durham, United Kingdom \\ bSchool of Chemistry and Molecular Biosciences and Australian Infectious Diseases Research Centre, The University of Queensland, St. Lucia, Australia \\ ‘Department of Microbiology and Immunology, University of Melbourne, at the Peter Doherty Institute for Infection and Immunity, Melbourne, Victoria, Australia \\ dBiosciences Institute, Faculty of Medical Sciences, Framlington Place, Newcastle University, Newcastle upon Tyne, United Kingdom \\ Louisa J. Stewart and Cheryl-lynn Y. Ong contributed equally to this article. Louisa J. Stewart is listed first for greater involvement in drafting the initial and revised manuscripts.
}

ABSTRACT Copper (Cu) is an essential metal for bacterial physiology but in excess it is bacteriotoxic. To limit $\mathrm{Cu}$ levels in the cytoplasm, most bacteria possess a transcriptionally responsive system for $\mathrm{Cu}$ export. In the Gram-positive human pathogen Streptococcus pyogenes (group A Streptococcus [GAS]), this system is encoded by the copYAZ operon. This study demonstrates that although the site of GAS infection represents a Cu-rich environment, inactivation of the copA $\mathrm{Cu}$ efflux gene does not reduce virulence in a mouse model of invasive disease. In vitro, Cu treatment leads to multiple observable phenotypes, including defects in growth and viability, decreased fermentation, inhibition of glyceraldehyde-3-phosphate dehydrogenase (GapA) activity, and misregulation of metal homeostasis, likely as a consequence of mismetalation of noncognate metal-binding sites by Cu. Surprisingly, the onset of these effects is delayed by $\sim 4 \mathrm{~h}$ even though expression of copZ is upregulated immediately upon exposure to $\mathrm{Cu}$. Further biochemical investigations show that the onset of all phenotypes coincides with depletion of intracellular glutathione (GSH). Supplementation with extracellular GSH replenishes the intracellular pool of this thiol and suppresses all the observable effects of $\mathrm{Cu}$ treatment. These results indicate that GSH buffers excess intracellular $\mathrm{Cu}$ when the transcriptionally responsive $\mathrm{Cu}$ export system is overwhelmed. Thus, while the copYAZ operon is responsible for Cu homeostasis, GSH has a role in Cu tolerance and allows bacteria to maintain metabolism even in the presence of an excess of this metal ion.

IMPORTANCE The control of intracellular metal availability is fundamental to bacterial physiology. In the case of copper (Cu), it has been established that rising intracellular Cu levels eventually fill the metal-sensing site of the endogenous Cu-sensing transcriptional regulator, which in turn induces transcription of a copper export pump. This response caps intracellular $\mathrm{Cu}$ availability below a well-defined threshold and prevents $\mathrm{Cu}$ toxicity. Glutathione, abundant in many bacteria, is known to bind $\mathrm{Cu}$ and has long been assumed to contribute to bacterial $\mathrm{Cu}$ handling. However, there is some ambiguity since neither its biosynthesis nor uptake is Cu-regulated. Furthermore, there is little experimental support for this physiological role of glutathione beyond measuring growth of glutathione-deficient mutants in the presence of Cu. Our work with group A Streptococcus provides new evidence that glutathione increases the threshold of intracellular Cu availability that can be tolerated by bacteria and thus advances fundamental understanding of bacterial $\mathrm{Cu}$ handling.

KEYWORDS copper homeostasis, copper export, metal buffer, glutathione, group A Streptococcus, copper stress, copper tolerance
Citation Stewart L, Ong C-LY, Zhang MM, Brouwer S, McIntyre L, Davies MR, Walker MJ, McEwan AG, Waldron KJ, Djoko KY. 2020. Role of glutathione in buffering excess intracellular copper in Streptococcus pyogenes. mBio 11:e02804-20. https://doi.org/10.1128/mBio .02804-20.

Editor Michael David Leslie Johnson, University of Arizona

Copyright $\odot 2020$ Stewart et al. This is an open-access article distributed under the terms of the Creative Commons Attribution 4.0 International license.

Address correspondence to Karrera Y. Djoko, karrera.djoko@durham.ac.uk.

Received 7 October 2020

Accepted 23 October 2020

Published 1 December 2020 
D acteria have been exposed to environmental copper $(\mathrm{Cu})$ since the Great Oxidation Event, when the rise in atmospheric $\mathrm{O}_{2}$ levels led to its solubilization from minerals. There is also evidence that recent evolution of plant, animal, and human pathogens has been influenced by the anthropogenic release of $\mathrm{Cu}$ into soils, for instance via mining activities and the legacy of using $\mathrm{Cu}$ salts and compounds in industrial-scale biocides (1). In addition, bacteria encounter elevated levels of $\mathrm{Cu}$ in microenvironments within a eukaryotic host. Bacterial predation induces an increase in intracellular Cu levels in protozoa (2), while phagocytosis stimulates uptake and accumulation of $\mathrm{Cu}$ in murine macrophages $(3,4)$. Studies of more complex animal models of infectious disease and human infections further suggest that infection triggers systemic changes in host $\mathrm{Cu}$ levels and that the specific sites of inflammation are usually, though not always, Cu-rich (5-9). The prevailing model is that $\mathrm{Cu}$ exerts a direct antibacterial action and/or supports the antibacterial function of innate immune cells (10).

$\mathrm{Cu}$ can be bacteriotoxic because it is a thermodynamically competitive metal for protein binding (11). Extracellular $\mathrm{Cu}$ invariably enters the bacterial cytoplasm via uptake processes that remain poorly understood. Once inside, $\mathrm{Cu}$ fills the available Cu-binding sites in proteins and other biomolecules, beginning with the tightest affinity and eventually associating with the weakest affinity sites. Within this hierarchy of binding sites are the allosteric sites in Cu-sensing transcriptional regulators, which, when metalated by $\mathrm{Cu}$, activate expression of a Cu efflux pump (12). In undertaking this role, the $\mathrm{Cu}$ sensor and export pump together impose an upper threshold of $\mathrm{Cu}$ availability in the cytoplasm. This system ensures that only native, stable, high-affinity $\mathrm{Cu}$ sites are metalated by $\mathrm{Cu}$, and at the same time, prevents adventitious, nonspecific, noncognate, weaker-binding sites from becoming mismetalated. Such mismetalation events can inactivate key enzymes and, consequently, impair bacterial growth and viability (13-16).

Additional cytoplasmic components are thought to limit $\mathrm{Cu}$ availability by chelating or "buffering" this metal ion. These components include bacterial metallothioneins (17), Cu storage proteins (18), and Cu-binding metallochaperones $(19,20)$, which are often, though not always, transcriptionally regulated by the endogenous $\mathrm{Cu}$ sensors. Mutant bacterial strains lacking these proteins typically display a $\mathrm{Cu}$-sensitive growth phenotype. Non-protein components, particularly the low-molecular-weight thiol glutathione (GSH), are also assumed to buffer $\mathrm{Cu}(21)$, although their uptake or biosynthesis is not transcriptionally induced in response to Cu treatment $(15,20,22,23)$. Addition of GSH protects purified metalloenzymes from inactivation by $\mathrm{Cu}$ (13). Growth of bacterial mutant strains that are impaired in GSH uptake (24) or biosynthesis (25-27) are all inhibited by added $\mathrm{Cu}$, especially if the Cu efflux pump $(25,26)$ or Cu-binding metallochaperone (27) in the organism is also inactivated.

Beyond growth analysis, there is currently little experimental support for a physiological role of GSH in buffering $\mathrm{Cu}$ in bacteria. Perhaps the clearest, albeit indirect, line of evidence was obtained using a $\Delta g s h B \Delta a t x 1$ mutant of Synechocystis lacking the GSH biosynthesis enzyme GshB and the cytoplasmic Cu-binding metallochaperone Atx1. This mutant failed to repress expression of $\mathrm{Zn}$-regulated genes in response to elevated $\mathrm{Zn}$ (27). In vitro metal- and DNA-binding experiments (28) suggest that the absence of GSH and the metallochaperone leads to an increase in intracellular Cu availability, which mismetalates the allosteric site of the Zn sensor Zur and thus interferes with Zn sensing.

Like most bacteria, the Gram-positive human pathogen Streptococcus pyogenes (group A Streptococcus [GAS]) possesses a system for Cu sensing and efflux, which is encoded by the copYAZ operon (29). In this work, we examine whether copA, encoding the Cu-effluxing $\mathrm{P}_{1 \mathrm{~B}-1}$-type ATPase, plays a critical role in GAS pathogenesis, as demonstrated for other bacterial pathogens (7, 30-32). We show that GAS occupies a Cu-rich environment during infection of a mouse model of invasive disease, and yet inactivation of copA does not significantly reduce GAS virulence. This unexpected observation leads us to investigate the effects of Cu treatment on the cellular biochemistry and physiology of GAS. The results provide key insights into the importance of GSH 
in cytoplasmic $\mathrm{Cu}$ buffering to supplement the transcriptionally responsive $\mathrm{Cu}$ sensing and efflux system. This additional buffering extends the range of intracellular $\mathrm{Cu}$ concentrations that can be tolerated by bacteria and thus prevents a sudden or abrupt transition from $\mathrm{Cu}$ homeostasis to $\mathrm{Cu}$ stress upon exposure to an excess of this metal ion.

\section{RESULTS}

Initial characterization of a $\Delta$ copA mutant. The copYAZ operon in GAS has been previously shown to resemble other Cop systems in Gram-positive bacteria (29) (see Fig. S1A in the supplemental material). Consistent with a role in $\mathrm{Cu}$ efflux, expression of this operon functionally complemented a heterologous Escherichia coli $\triangle$ copA mutant strain (29). In silico analyses found one additional open reading frame downstream of copZ (see Fig. S1A). It encodes a small, uncharacterized protein (56 amino acids) with an $\mathrm{N}$-terminal transmembrane domain, a putative metal-binding $\mathrm{C}-\mathrm{X}_{3}-\mathrm{M}-\mathrm{H}$ motif at the $\mathrm{C}$ terminus, and no characterized homologue. This gene is absent from copYAZ operons in other Gram-positive bacteria and its function in Cu homeostasis is unknown.

For the present study, a non-polar $\triangle$ copA mutant of GAS M1T1 strain 5448 was constructed. This mutation did not alter basal expression of downstream cop genes (see Fig. S1Bi). As anticipated, the $\triangle c o p A$ mutant was more susceptible to growth inhibition by added $\mathrm{Cu}$ than was the wild type (see Fig. S1C). This mutant also accumulated more intracellular $\mathrm{Cu}$ (see Fig. S1D), leading to increased expression of the other cop genes compared to the wild type (see Fig. S1Bii). Marker rescue $\left(c o p A^{+}\right)$restored the expression of both copA and wild-type phenotypes (see Fig. S1B to D).

Deletion of copA does not lead to a loss of virulence in a mouse model of infection. To determine whether the Cop system and its interactions with host Cu have an effect on GAS pathogenesis, an established invasive disease model using transgenic human-plasminogenized mice was used (33). Mice subcutaneously infected with wildtype GAS developed ulcerative skin lesions at the site of injection after 1 day. These lesions were excised 3 days post-infection and were found to contain more $\mathrm{Cu}$ than adjacent healthy skin or skin from uninfected mice (Fig. 1A). Consistent with these results, the copYAZ operon was upregulated in GAS isolated from infected mouse tissues compared to those grown in THY medium (34). There was also an increase in $\mathrm{Cu}$ levels in mouse blood after 3 days of infection (Fig. 1B). Notably, these Cu levels in the blood are comparable to those measured in the sera of mice infected with the fungal pathogen Candida albicans or the parasite Plasmodium berghei (5). These observations support a model where redistribution of host $\mathrm{Cu}$ is a feature of the general immune response to infection (5).

Comparing the survival of mice post-infection, no statistically significant difference was observed whether mice were infected with the wild type or the $\Delta$ copA mutant $(P=0.0991$; Fig. 1C). Although no single animal model can fully represent the complex features of human streptococcal diseases (35), consistent with in vivo findings, the $\triangle c o p A$ mutant was no more susceptible to killing by human neutrophils compared with the wild-type or copA $A^{+}$mutant strains in an ex vivo infection assay (Fig. 1D). In addition, recent reports did not identify the cop genes to be fitness determinants during ex vivo infection of human blood (36) or in vivo soft tissue infection in mice (37). These results imply that, despite the systemic and niche-specific elevated levels of host $\mathrm{Cu}$, the $\mathrm{Cu}$ efflux pump CopA is not essential for GAS virulence in this model.

$\mathrm{Cu}$ treatment leads to defects in the late exponential phase of growth. The lack of a virulence defect for the $\Delta c o p A$ mutant in vivo prompted us to examine the impact of Cu treatment on GAS physiology in vitro. Addition of $\mathrm{Cu}$ (up to $10 \mu \mathrm{M}$ ) to the culture medium did not affect the doubling time of the $\triangle$ copA mutant during the exponential phase of growth, but it did reduce the final culture yield (Fig. 2A; see Fig. S2A and B). This phenotype was reproduced during growth in the presence of glucose or alternative carbon sources (see Fig. S2C). Under each condition, growth of Cu-treated cultures ceased upon reaching approximately the same optical density at $600 \mathrm{~nm}\left(\mathrm{OD}_{600}\right.$; $\sim 0.35$ ) regardless of growth rate, indicating that the growth defect was related to 
(A)

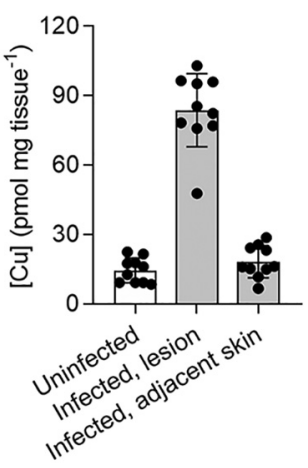

(C)

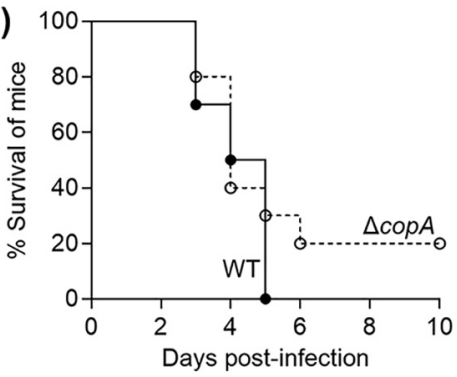

(B) 307 Uninfected Infected
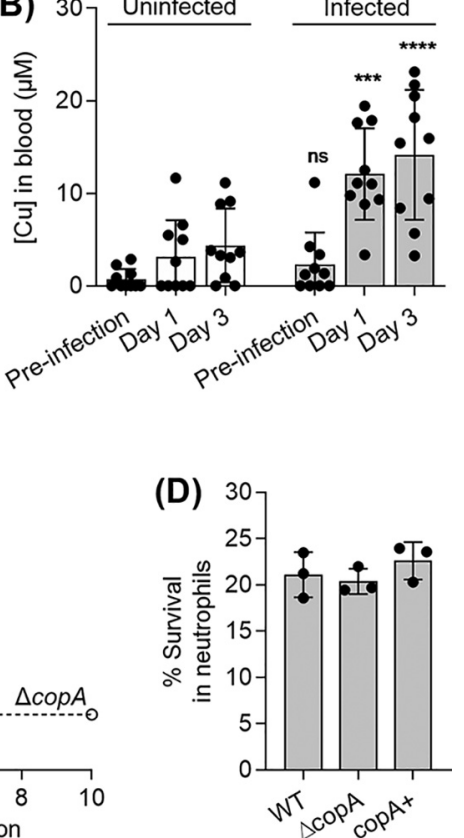

FIG 1 Changes in Cu levels during GAS infection and the effect of a copA mutation on GAS virulence in host infection models. (A) $\mathrm{Cu}$ levels in mouse lesions. Mice were infected subcutaneously with GAS wild-type strain or left uninfected ( $n=10$ each). After 3 days, skin from uninfected mice, and both skin lesions and healthy skin adjacent to the lesions from infected mice were excised. Total Cu levels were measured by ICP-MS and normalized to the weight of the tissues. Cu levels in infected lesions were higher than those in adjacent healthy skin $(P<0.0001)$ or skin from uninfected mice $(P<0.0001)$. (B) $\mathrm{Cu}$ levels in mouse blood. Mice were infected subcutaneously with GAS wild-type strain or left uninfected ( $n=10$ each). Blood was collected and total Cu levels were measured by ICP-MS. Values below the detection limit were represented as zero. Cu levels in the blood of infected mice on days 1 and 3 were higher from those in the blood of uninfected mice $\left.{ }^{* * *}, P=0.0001 ;{ }^{* * *}, P<0.0001\right)$. ns, $P=0.81$ (versus uninfected mice). (C) Virulence in an in vivo mouse model of infection. Mice were infected subcutaneously with GAS wild-type (WT) or $\triangle \operatorname{copA}$ mutant strains ( $n=10$ each). The number of surviving mice was counted daily up to 10 days post-infection. Differences in survival curves were analyzed using the Mann-Whitney test, which found no statistical difference $(P=0.099)$. (D) Virulence in an ex vivo human neutrophil model of infection. Human neutrophils were infected with GAS wild-type (WT), $\triangle \operatorname{copA}$, or $\operatorname{cop} A^{+}$strains ( $n=3$ each). Survival of bacteria relative to the input was measured after $0.5 \mathrm{~h}$. There was no difference between survival of the $\triangle \operatorname{cop} A$ mutant compared with the WT $(P=0.87)$ or $\operatorname{cop} A^{+}(P=$ $0.35)$ strains.

bacterial cell numbers and/or growth stage. Consistent with this interpretation, $\mathrm{Cu}$ treatment did not affect growth in the presence of mannose (see Fig. S2C) or limiting amounts of glucose (see Fig. S2D), since neither experimental condition supported growth of GAS beyond an $\mathrm{OD}_{600}$ of $\sim 0.35$.

Parallel assessments of plating efficiency and total ATP levels confirmed that differences between Cu-treated and untreated cultures appeared only in the late exponential or early stationary phase of growth (after $\sim 4 \mathrm{~h}$ when grown in the presence of glucose; Fig. 2B and $\mathrm{C}$ ). There were clear decreases in the plating efficiency and ATP production by Cu-treated $\triangle \operatorname{copA}$ cultures during this period compared to the untreated control.

Cu treatment leads to metabolic arrest in the late exponential phase of growth. GAS is a lactic acid bacterium. Under our experimental conditions, this organism carried out homolactic fermentation and generated lactic acid as the major end product (see Fig. S3A and B). However, Cu-treated $\triangle$ copA cultures did not acidify the growth medium (see Fig. S3C), leading us to hypothesize that Cu treatment impairs fermentation in GAS.

Consistent with this proposal, Cu-treated $\triangle$ copA cultures produced $\sim 50 \%$ less lactic acid and consumed $\sim 50 \%$ less glucose compared to the untreated control (Fig. 3A; see also Fig. S3Bi and ii). Pyruvate production remained unchanged (see Fig. S3Biii). There is no evidence of a shift toward mixed-acid fermentation since the reduction in lactate 

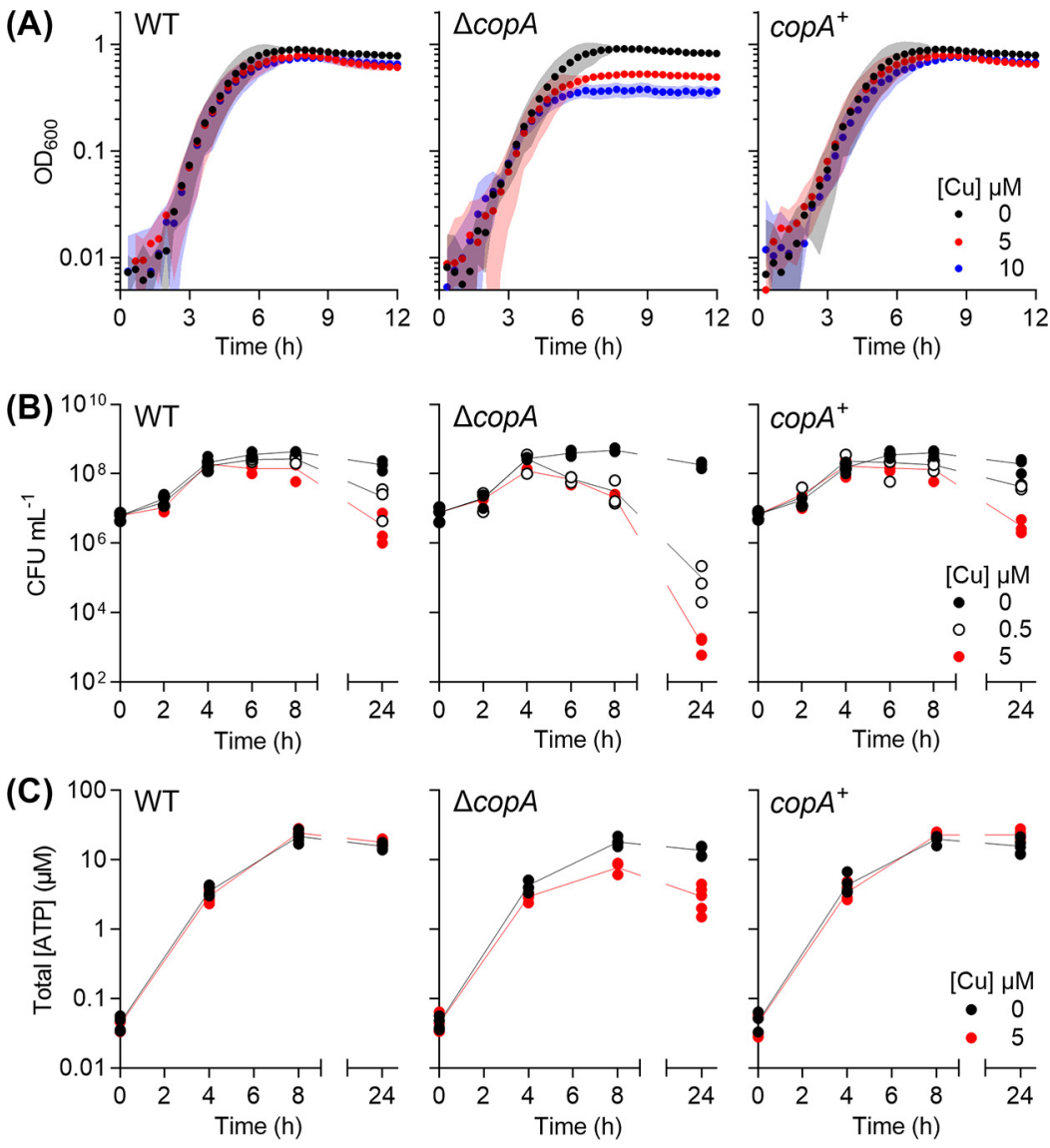

FIG 2 Cu-dependent defects in growth and viability. GAS strains were cultured with added $\mathrm{Cu}$ as indicated. (A) Growth. Cultures $(n=3)$ were grown in microtiter plates and $\mathrm{OD}_{600}$ values were recorded every $20 \mathrm{~min}$. Cu treatment suppressed growth of $\triangle$ copA cultures $(P=0.034$ for $5 \mu \mathrm{M} \mathrm{Cu}, P<0.0001$ for $10 \mu \mathrm{M}(\mathrm{Cu})$. (B) Plating efficiency. Cultures $(n=3)$ were plated out at the indicated time points and the number of CFU was enumerated. Cu treatment suppressed plating efficiency of the $\triangle$ copA cultures $(P<$ 0.0001 for both 0.5 and $5 \mu \mathrm{M} \mathrm{Cu}$ ). (C) Total ATP levels. Cultures $(n=5)$ were sampled at the indicated time points and total ATP levels were determined. Cu treatment suppressed ATP production in the $\triangle$ copA cultures $(P<0.0001)$. All statistical analyses were versus $0 \mu \mathrm{M} \mathrm{Cu}$.

levels was not accompanied by a concomitant increase in acetate levels (see Fig. 3Biv). Ethanol levels were undetectable (detection limit, $\sim 0.2 \mathrm{mM}$ ).

Differences in lactate production between Cu-treated and untreated $\triangle$ copA cultures appeared, again, only after $\sim 4 \mathrm{~h}$ of growth (Fig. 3A). While our methods are not sufficiently sensitive to detect small changes in glucose levels at earlier time points, it is clear that Cu-treated $\triangle$ copA cultures did not consume glucose beyond $t \sim 4 \mathrm{~h}$ (see Fig. S3Di). Pyruvate production was, again, not affected at any time point (see Fig. S3Dii). These results suggest that $\mathrm{Cu}$ treatment leads to defects in metabolism but only after entry into the late exponential phase of growth.

Cu treatment results in a loss of GapA activity in the late exponential phase of growth. The loss of lactate production, but not pyruvate, implies that lactate dehydrogenase (Ldh) is inactivated (Fig. 3B). To test this proposal, we cultured GAS in the absence or presence of added $\mathrm{Cu}$ for $4 \mathrm{~h}$, prepared whole-cell extracts, and measured Ldh activity. Figure $3 \mathrm{Ci}$ and $3 \mathrm{Di}$ show that $\mathrm{Ldh}$ remained active in all strains, regardless of $\mathrm{Cu}$ treatment.

What, then, is the target of $\mathrm{Cu}$ intoxication in GAS? This bacterium does not possess a tricarboxylic acid cycle or the biosynthesis pathways for multiple amino acids, vitamins, and cofactors (e.g., heme). Thus, it lacks obvious candidate iron-sulfur cluster enzymes that are destabilized by excess $\mathrm{Cu}$ ions in other systems (13). In an attempt to develop a molecular explanation for the loss of fermentation, the activity of the two 


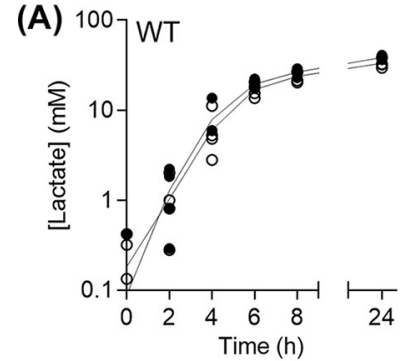

(C)

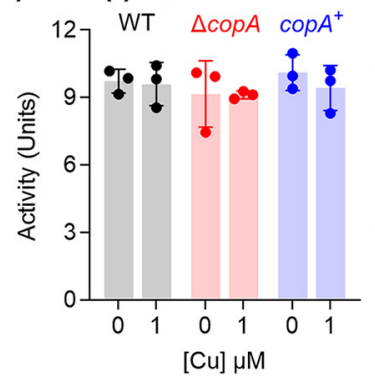

(D)

(i) Ldh

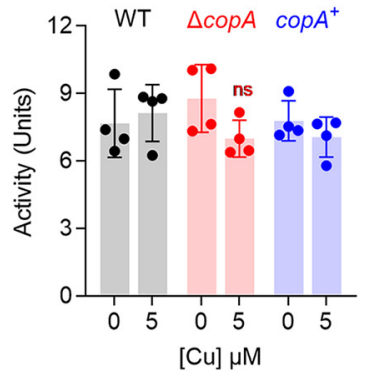

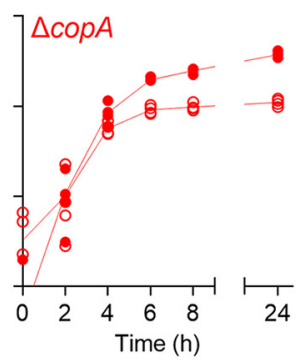

(ii) GapA

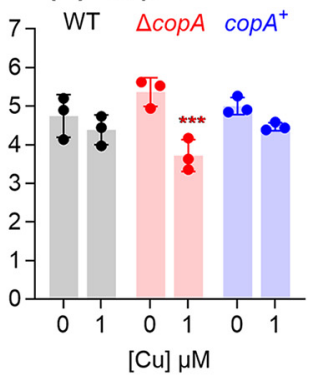

(ii) GapA

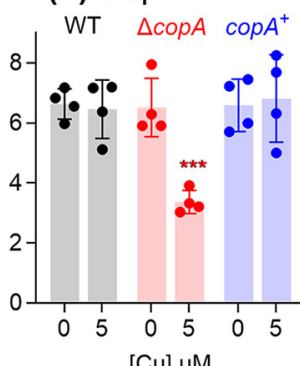

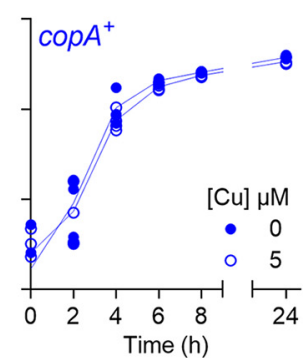

(iii) GapN

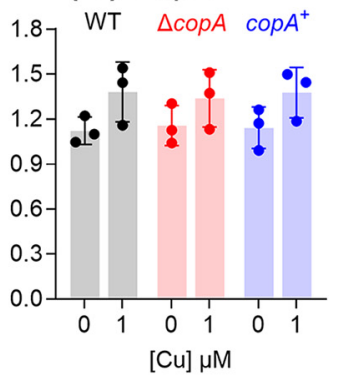

(B) Glucose

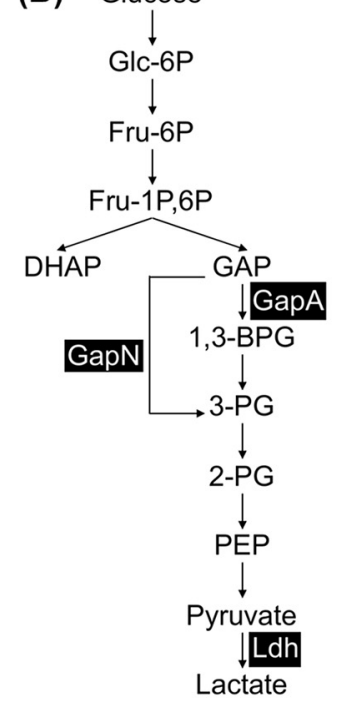

(E) GapA

$2 \mathrm{~h} \quad 3 \mathrm{~h} \quad 4 \mathrm{~h}$

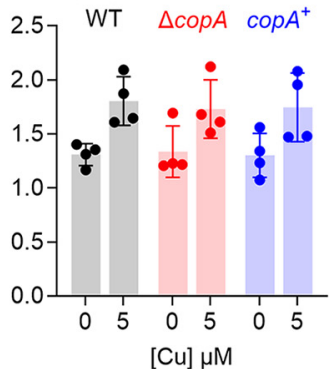

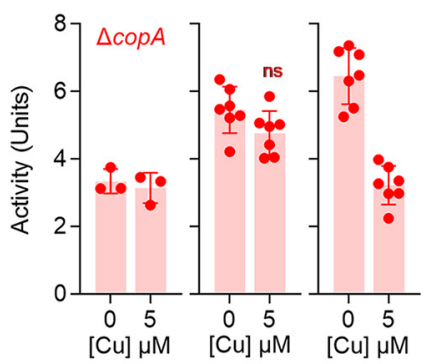

FIG 3 Cu-dependent defects in glycolysis and homolactic fermentation. (A) Lactate production. GAS strains were cultured with added $\mathrm{Cu}$ as indicated $(n=3)$. Amounts of lactate secreted to the extracellular culture medium were measured at the indicated time points. Cu treatment suppressed lactate production in the $\triangle$ copA cultures $(P<0.0001)$. (B) Fermentation pathway in GAS. Enzymes of interest, namely, GapA (NAD+-dependent GAPDH, M5005_SPy_0233), GapN (NADP+-dependent GAPDH, M5005_SPy_1119), and Ldh (lactate dehydrogenase, M5005_SPy_0873) are shown. (C and D) Activity of glycolytic enzymes Ldh (i), GapA (ii), and GapN (iii). GAS strains were cultured for $t=4 \mathrm{~h}$ with 0 or $1 \mu \mathrm{M}$ added $\mathrm{Cu}(n=3)(\mathrm{C})$ or 0 or $5 \mu \mathrm{M}$ added $\mathrm{Cu}(n=4)(\mathrm{D})$. Enzyme activities were determined in cell extracts. Cu treatment decreased GapA activity in $\triangle$ copA cultures ( $\left.{ }^{* *}, P=0.0004\right)$. ns, $P=0.14$. (E) GapA activity over time. GAS $\triangle \operatorname{cop} A$ mutant strain was cultured with added $\mathrm{Cu}$ as indicated for $t=2 \mathrm{~h}(n=3), 3 \mathrm{~h}(n=7)$, or $4 \mathrm{~h}(n=7)$. Enzyme activities were determined in cell extracts. Cu treatment did not have an effect on GapA activity at $t=2 \mathrm{~h}(P=0.99)$ or $3 \mathrm{~h}$ (ns, $P=0.18)$, but it strongly inhibited GapA activity at $t=4 \mathrm{~h}(P<0.0001)$. All statistical analyses were versus $0 \mu \mathrm{M} \mathrm{Cu}$.

GAPDH (glyceraldehyde-3-phosphate dehydrogenase) enzymes in GAS, namely, the classical, phosphorylating, ATP-generating GapA and the alternative, nonphosphorylating GapN, was examined (Fig. 3B). GapA has been identified as a target of Ag and Cu poisoning in E. coli (38) and Staphylococcus aureus (39), respectively, and as such, it is a likely candidate for Cu poisoning in GAS. As expected, Cu treatment led to a decrease in GapA activity in $\triangle$ copA mutant cells (Fig. 3Cii and Dii), which would explain the reduction in lactate secretion (Fig. $3 \mathrm{~A}$ ) and ATP production (Fig. $2 \mathrm{C}$ ). The reduction in GapA activity would also cause upstream glycolytic precursors to accumulate, with consequent feedback inhibition of downstream enzymes (40), as well as glucose phosphorylation and uptake (see Fig. S3Bii and S3Di) $(41,42)$.

This Cu-dependent inhibition is specific to GapA since there was no reduction in GapN activity (Fig. 3Ciii and Diii). Given that there was no detectable change in GapA protein levels in cell extracts (see Fig. S3E), these observations are consistent with mismetalation of GapA, as established recently for the GapA homologue in S. aureus (39). The excess $\mathrm{Cu}$ ions likely bind to the conserved Cys and His residues at the catalytic site, as suggested previously for the binding of Ag ions to GapA from E. coli (38). 
Remarkably, when cultures were sampled earlier (at $t=2$ and $3 \mathrm{~h}$ ), no difference was observed between GapA activity in Cu-treated and control $\triangle$ copA cells (Fig. 3E). The timing of GapA inhibition, i.e., at the onset of the late exponential phase of growth (at $t=4 \mathrm{~h}$; Fig. 3E), coincided with the arrest in bacterial growth and metabolism, supporting the hypothesis that GapA is a key target of $\mathrm{Cu}$ intoxication in GAS.

Cu treatment leads to misregulation of metal homeostasis in late exponential phase of growth. The puzzling but consistent, 4-h delay in the onset of all observable phenotypes led us to hypothesize that there was a time-dependent shift in Cu handling by GAS. To test this proposal, the response of the Cu sensor CopY was measured by monitoring expression of copZ during growth in the presence of the lowest inhibitory concentration of added $\mathrm{Cu}(0.5 \mu \mathrm{M}$; see Fig. S2Aii). The results show that copZ transcription was upregulated $\sim 4$-fold immediately upon $\mathrm{Cu}$ exposure $(t=0 \mathrm{~h}$, in which $\sim 12$ min passed between the addition of $\mathrm{Cu}$ into the culture, centrifugation, and the addition of lysis buffer; Fig. 4A). This level of upregulation remained largely unchanged during growth (measured up to $5 \mathrm{~h}$; Fig. 4A), even though intracellular $\mathrm{Cu}$ levels continued to rise (see Fig. S4). These results suggest that the CopY sensor became fully metalated and expression of $c o p Z$ reached its maximum at $t=0 \mathrm{~h}$ post-challenge with added $\mathrm{Cu}$. These data also establish that the copYAZ operon is transcriptionally induced before the onset of observable growth defects (hereafter referred to as Cu "stress").

We concurrently measured the expression of genes that are controlled by other metalloregulators, namely adcAll (regulated by AdcR, a MarR-family Zn-sensing transcriptional corepressor [43]), siaA (controlled by MtsR, a DtxR-family Mn/Fe-sensing corepressor [44]), and cadD (regulated by CadC, an ArsR-family Zn/Cd-sensing derepressor [45]). Clear changes in the expression levels of all three genes were detected in response to $\mathrm{Cu}$ treatment. While adcAll and siaA were downregulated, cadD was upregulated (Fig. 4B to D). Each of these transcriptional responses indicates metalation of the corresponding metallosensor (Fig. 4B to D), but whether by the cognate metal or by $\mathrm{Cu}$ cannot be distinguished. These observations were further corroborated by results from genome-wide RNA sequencing (RNA-seq) analyses. Multiple AdcR- and MtsR-controlled genes were negatively regulated, while both the CadC-controlled genes were positively regulated in response to $5 \mu \mathrm{M}$ added $\mathrm{Cu}$ (Table 1; see Data Set S1). Interestingly, no clear effect on $g c z A$ or $C z c D$ expression was detected, suggesting that the metalation status of GczA, a TetR-family Zn-sensing derepressor (46), is not altered by $\mathrm{Cu}$ treatment.

Crucially, changes in the expression of adcAll, siaA, and cadD appeared only after $\sim 4$ $h$ of growth (Fig. $4 B$ to $D$ ). These transcriptional changes were not accompanied by increases in total intracellular Zn, Mn, or Fe levels (see Fig. S4). Thus, the simplest model that accounts for the sudden metalation (or mismetalation) of multiple metallosensors, as well as GapA, is that excess $\mathrm{Cu}$ is released from an intracellular buffer, leading to mislocation of $\mathrm{Cu}$ to adventitious binding sites and/or redistribution of intracellular metals.

The onset of the $\mathrm{Cu}$ stress phenotype coincides with depletion of GSH. What comprises the intracellular buffer for excess $\mathrm{Cu}$ in GAS? This organism does not possess a homologue of the metallothionein MymT (17) or the Cu storage protein Csp (47). Instead, this buffer likely consists of a polydisperse mixture of cytoplasmic small molecules or metabolites (48). Noting that GAS is auxotrophic for most nutrients, including multiple amino acids, vitamins, nucleobases, and GSH, we hypothesized that: (i) one or more of these nutrients constitute the intracellular Cu buffer, either directly by coordinating $\mathrm{Cu}$ or indirectly by acting as a synthetic precursor to the buffer, and that (ii) these nutrients become exhausted from the extracellular medium during bacterial growth, leading to the observable effects of Cu stress.

The above hypothesis was tested using two complementary approaches and the results identified GSH as the key limiting nutrient. First, mass spectrometry was employed to measure consumption of nutrients from the growth medium. Several amino acids, the nucleobases adenine and uracil, as well as GSH (and/or its disulfide GSSG) 
(A) $\operatorname{cop} Z$
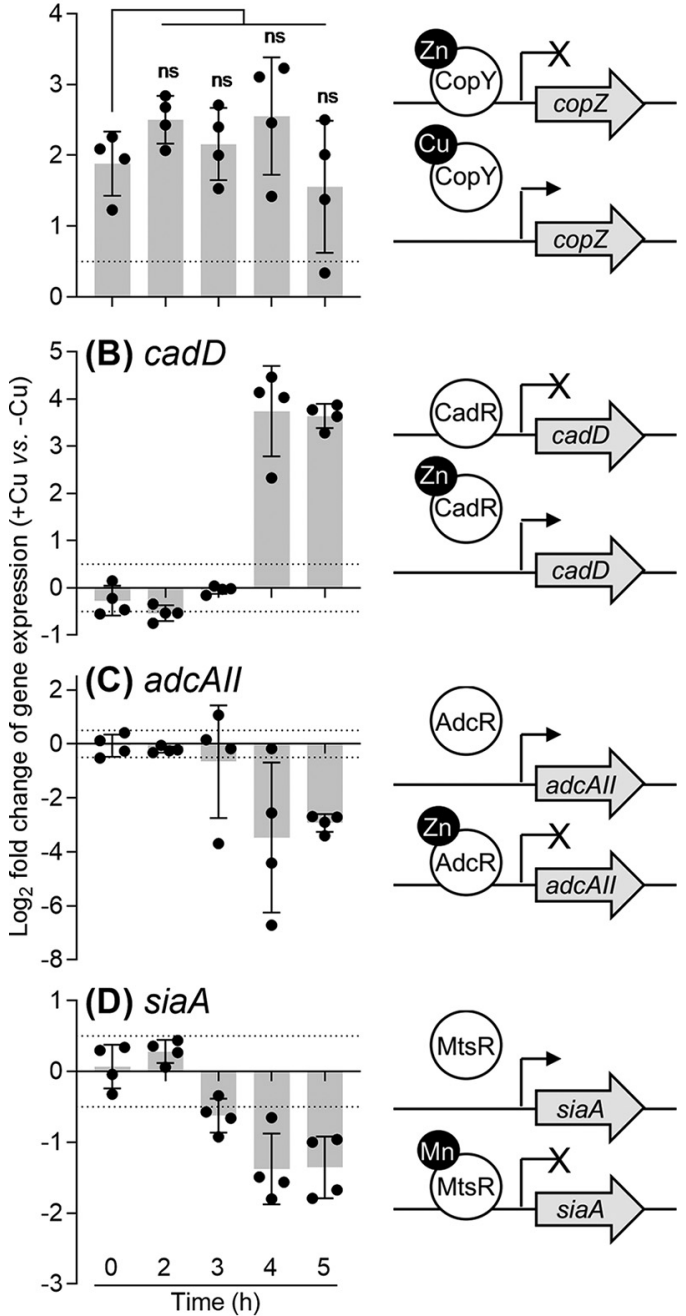

FIG 4 Cu-dependent misregulation of metal homeostasis genes. GAS $\triangle$ copA mutant strain was cultured with or without added $0.5 \mu \mathrm{M}$ Cu for the indicated times $(n=4)$. Transcript levels in Cu-treated cultures were determined by qPCR and normalized to the corresponding untreated samples that were cultured for the same time periods. Dotted horizontal lines represent the limit of the assay $\left(\log _{2} F C= \pm 0.5\right)$. A schematic representation of each gene and its cognate metallosensor is shown. Transcription of copZ or $c a d D$ is derepressed upon binding of $\mathrm{Cu}$ to $\mathrm{CopY}$ or $\mathrm{Zn}$ (or $\mathrm{Cd}$ ) to CadR, respectively. Transcription of adcAll or siaA is repressed upon binding of $\mathrm{Zn}$ to AdcR or Mn (or Fe) to MtsR, respectively. (A) copZ. Cu treatment induced copZ expression $t=0 \mathrm{~h}\left(P=0.0037\right.$ versus $\left.\log _{2} \mathrm{FC}=0\right)$. This magnitude of induction remained unchanged over the growth period (ns, $P=0.53,0.94,0.47$, and 0.90 for $t=2,3,4$, and $5 \mathrm{~h}$, respectively, versus $t=0 \mathrm{~h})$. (B) cadD. Cu treatment upregulated cadD expression at $t=4$ and $5 \mathrm{~h}(P=$ 0.0044 and $<0.0001$, respectively, versus $\log _{2} F C=0$ ). (C) adcAll. Cu treatment downregulated adcAll expression at $t=4$ and $5 \mathrm{~h}\left(P=0.035\right.$ and 0.0004 , respectively, versus $\left.\log _{2} \mathrm{FC}=0\right)$. (D) siaA. Cu treatment downregulated siaA expression at $t=3,4$, and $5 \mathrm{~h}(P=0.014,0.012$, and 0.084 , respectively, versus $\log _{2} \mathrm{FC}=0$ ).

were nearly or completely spent after $\sim 4 \mathrm{~h}$ of growth (see Fig. S5). Cys and its disulfide were below detection limits. Next, the culture medium was supplemented with each or a combination of the spent or undetected extracellular nutrients. Their ability to restore growth of Cu-treated $\triangle c o p A$ mutant cultures was subsequently examined. Only supplementation with GSH was strongly protective against $\mathrm{Cu}$ intoxication (see Fig. S6).

The GAS genome encodes neither the common pathway for GSH biosynthesis (GshAB) nor the bifunctional glutathione synthetase (GshF [49]). Instead, an uncharacterized homologue of the GSH-binding solute-binding protein GshT is present (M5005_Spy0270, 59\% sequence identity, 74\% sequence similarity with the characterized homologue from S. mutans) (50). GshT, in conjunction with the endogenous 
TABLE $1 \mathrm{Cu}$ treatment leads to a misregulation of metal homeostasis ${ }^{a}$

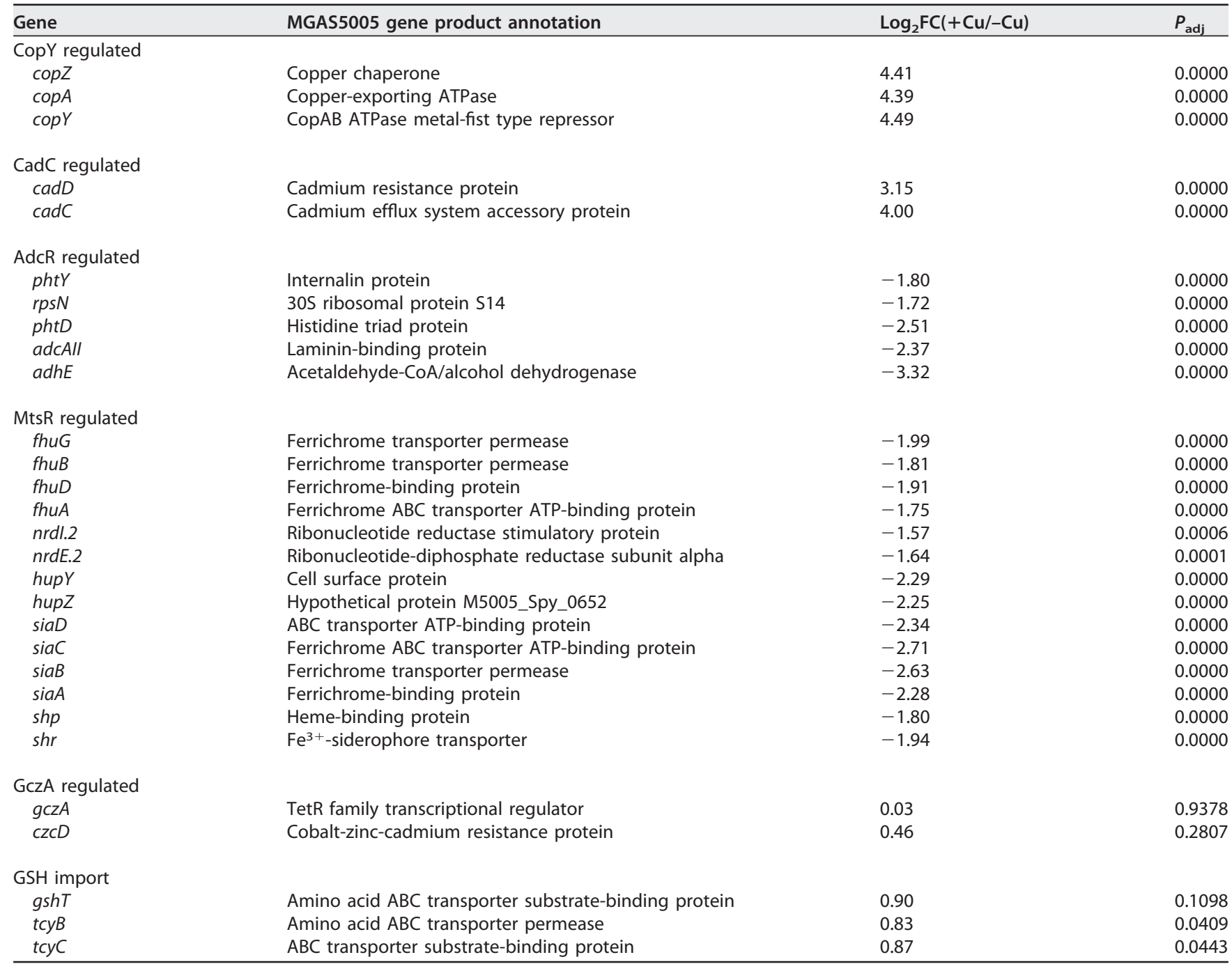

${ }^{a}$ GAS $\triangle$ copA mutant strain was cultured with or without $5 \mu \mathrm{M}$ added Cu for $t=5 \mathrm{~h}(n=3)$. Total RNA was extracted, rRNA was depleted, and cDNA was generated and finally sequenced by Illumina. Differential gene expression was determined using DeSeq 2 and is presented as the fold change (FC) in gene expression in the Cutreated cultures relative to that in the untreated control. Only genes of interest are listed. These are genes regulated by metal-sensing transcriptional regulators CopY, CadC (45), AdcR (43), MtsR (44), and GczA (46), as well as those that encode components of the putative GSH uptake system (50). A complete list of differentially regulated genes is provided in Data Set $\mathrm{S} 1$.

cystine importer TcyBC, likely allows GAS to import extracellular GSH ( $\gamma$-Glu-Cys-Gly) into the cytoplasm (50). This system may also import $\gamma$-Glu-Cys or Cys-Gly (50), but addition of these dipeptides, or Cys alone, or a mixture of the amino acids Glu, Cys, and Gly did not improve growth of Cu-treated $\triangle$ copA mutant cultures (Fig. 5A). Altogether, these results suggest that: (i) the protective effect of GSH is unlikely to result from chelation of extracellular Cu ions by free thiols, (ii) extracellular GSH is depleted during growth of GAS, and (iii) this depletion is responsible for the observable Cu stress phenotypes. Consistent with propositions ii and iii, addition of GSH completely suppressed the effects of Cu treatment and restored plating efficiency, as well as glucose consumption, lactate secretion, and ATP production beyond the late exponential phase of growth (Fig. 5B to E).

GSH contributes to buffering of excess intracellular $\mathbf{C u}$. To test that the protective effect of GSH is not linked to chelation of extracellular $\mathrm{Cu}$ ions and decreased uptake of $\mathrm{Cu}$ into the cytoplasm, total intracellular $\mathrm{Cu}$ levels were measured in $\triangle \mathrm{cop} A$ mutant cultures that were supplemented with $\mathrm{Cu}$ and/or GSH. As expected, GSH supplementation did not suppress total intracellular $\mathrm{Cu}$ levels when $\triangle$ copA cultures 

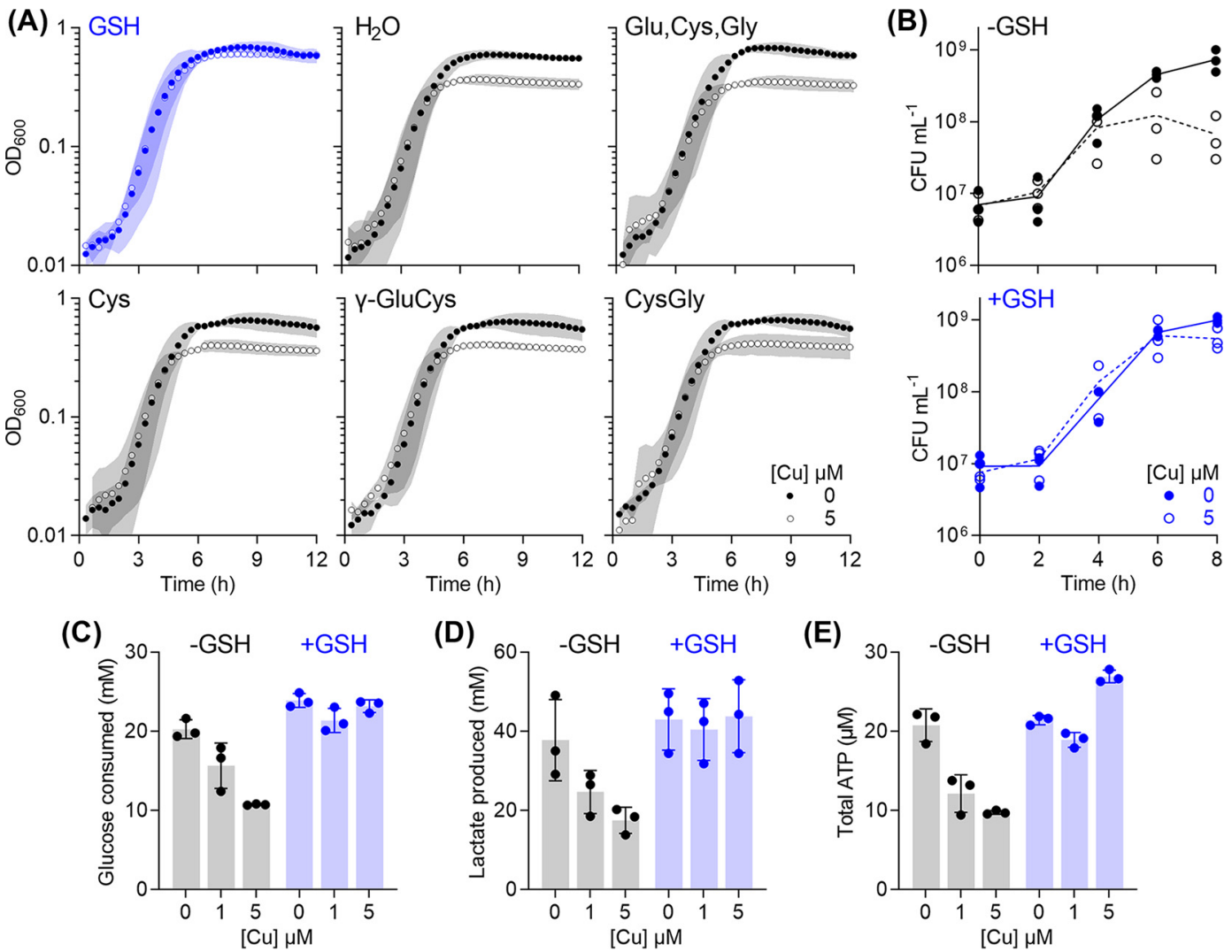

FIG 5 Protective effects of supplemental GSH. GAS $\Delta$ copA mutant strain was cultured with added Cu as indicated ( $n=3$ ) in the absence (black) or presence (blue) of $0.1 \mathrm{mM} \mathrm{GSH}$. (A) Growth. Cu treatment did not affect GSH-supplemented cultures $(P=0.99)$. Growth curves in culture medium supplemented with water; a mixture of Glu, Cys, and Gly ( $0.1 \mathrm{mM}$ each); Cys alone $(0.1 \mathrm{mM})$; the dipeptide $\gamma$-GluCys $(0.1 \mathrm{mM})$; or CysGly $(0.1 \mathrm{mM})$ are also shown for comparison. (B) Plating efficiency. Cultures were plated out at the indicated time points and the numbers of CFU were enumerated. Cu treatment suppressed plating efficiency of GSH-deplete cultures $(P=0.0012)$ but not that of the GSH-supplemented cultures $(P=0.97)$. (C) Glucose consumption. Cultures were sampled at $t=8 \mathrm{~h}$, and total amounts of glucose consumed from the extracellular growth media were determined. $\mathrm{Cu}$ treatment suppressed glucose consumption by GSH-deplete cultures $(P=0.0053$ for $1 \mu \mathrm{M}$ Cu, $P<0.0001$ for $5 \mu \mathrm{M} \mathrm{Cu}$ ) but not that by GSH-supplemented cultures $(P=0.12$ for $1 \mu \mathrm{M} \mathrm{Cu}, P=0.81$ for $5 \mu \mathrm{M}$ Cu). (D) Lactate production. Cultures were sampled at $t=8 \mathrm{~h}$, and the amounts of lactate secreted to the extracellular growth media were determined. Cu treatment suppressed lactate production by GSH-deplete cultures $(P=0.11$ for $1 \mu \mathrm{M} \mathrm{Cu}, P=0.014$ for $5 \mu \mathrm{M}$ $\mathrm{Cu}$ ) but not that by GSH-supplemented cultures ( $P=0.91$ for $1 \mu \mathrm{M} \mathrm{Cu}, P=0.99$ for $5 \mu \mathrm{M} \mathrm{Cu}$ ). (E) Total ATP levels. Cultures were sampled at $t=8 \mathrm{~h}$ and total ATP levels were determined. Cu treatment suppressed ATP production by GSH-depleted cultures $(P<0.0001$ each for 1 and $5 \mu \mathrm{M} \mathrm{Cu})$ but not that by the GSH-supplemented cultures $(P=0.095$ for $1 \mu \mathrm{M} \mathrm{Cu}, P=$ 0.0008 for $5 \mu \mathrm{M} \mathrm{Cu}$ ). All statistical analyses were versus $0 \mu \mathrm{M} \mathrm{Cu}$.

were challenged with low concentrations of added $\mathrm{Cu}(500 \mathrm{nM}$; Fig. 6A). Surprisingly, at high concentrations of added $\mathrm{Cu}(5 \mu \mathrm{M}), \mathrm{GSH}$-replete cultures appeared to accumulate higher, rather than lower, intracellular Cu levels (Fig. 6A). Yet, these cultures did not display an observable Cu stress phenotype (Fig. 5). These findings are discussed below.

The time-dependent reduction in extracellular GSH levels (see Fig. S5D) was mirrored by a decrease in intracellular GSH (Fig. 6Bi). Both the wild-type and $\triangle$ copA mutant strains contained $\sim 4 \mathrm{mM}$ intracellular GSH (and GSSG) at $t=0 \mathrm{~h}$ (Fig. 6Bi). This amount was likely already present in the inoculum, which was cultivated in the complex medium THY $\left([\mathrm{GSH}]_{\mathrm{THY}} \sim 30 \mu \mathrm{M}\right.$ [51]). Intracellular GSH levels in both strains reduced to $\sim 0.1 \mathrm{mM}$ at $t=4 \mathrm{~h}$, regardless of $\mathrm{Cu}$ treatment (Fig. 6Bi and ii). This decrease occurred presumably as a consequence of bacterial growth and replication in a chemically defined medium with a limited GSH supply $\left([G S H]_{\mathrm{CDM}} \sim 0.5 \mu \mathrm{M}\right.$; see Fig. S5D). The low amount of intracellular GSH coincided with the onset of the observable $\mathrm{Cu}$ stress phenotypes. It might also explain why cultures that grew to low $\mathrm{OD}_{600}$ values displayed no sign of $\mathrm{Cu}$ stress (see Fig. S2C and D); these cultures likely had not depleted their intracellular GSH supply. 

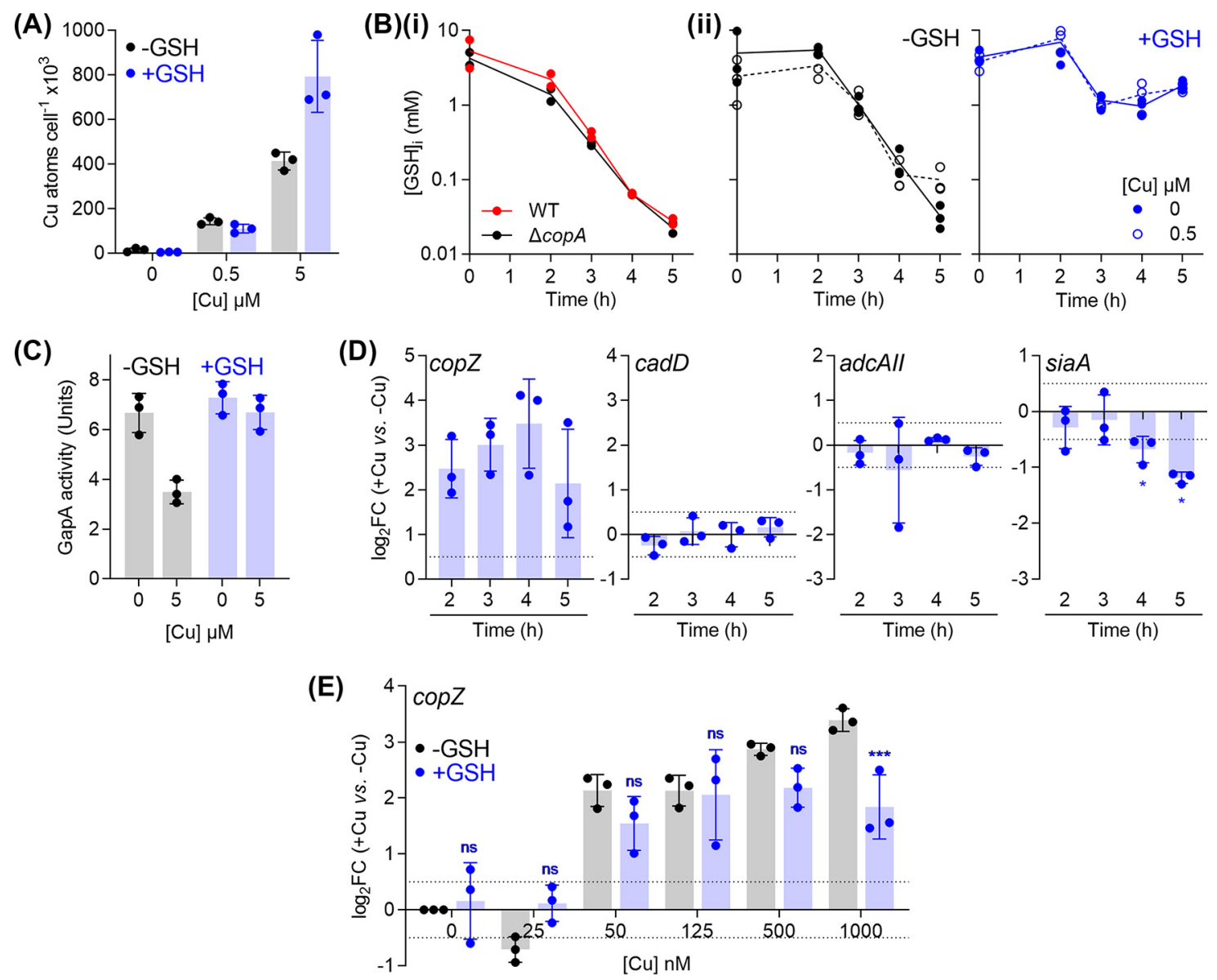

FIG 6 Buffering of excess intracellular Cu ions by GSH. GAS $\triangle$ copA mutant strain was cultured with added Cu as indicated, without (black) or with (blue) $0.1 \mathrm{mM}$ added GSH. The following properties were subsequently measured. (A) Intracellular Cu levels. Cultures $(n=3)$ were harvested at $t=4 \mathrm{~h}$, and total cellular levels of $\mathrm{Cu}$ were measured by ICP-MS. GSH supplementation did not affect intracellular $\mathrm{Cu}$ levels when cultures were treated with $0(P=1)$ or $0.5 \mu \mathrm{M} \mathrm{Cu}(P=0.92)$, but it did lead to an increase in Cu levels when cultures were treated with $5 \mu \mathrm{M} \mathrm{Cu}(P<0.0001)$. (B) Intracellular GSH concentrations. (i) Cultures $(n=2)$ were prepared without any added $\mathrm{Cu}$ or GSH and sampled at the indicated time points. Intracellular levels of GSH were measured in cell extracts. There was no clear difference between the time-dependent decrease in intracellular GSH levels of WT and $\Delta$ copA cultures. (ii) Cultures ( $n=3$ ) were sampled at the indicated time points and intracellular levels of GSH were measured in cell extracts. Cu treatment did not affect intracellular GSH levels, regardless of GSH supplementation ( $P=0.95$ for $0 \mathrm{mM} \mathrm{GSH}, P=1.0$ for $0.1 \mathrm{mM} \mathrm{GSH})$. GSH supplementation improved intracellular GSH levels $(P<0.0001$ for both 0 and $0.5 \mu \mathrm{M} \mathrm{Cu})$, regardless of Cu treatment. (C) GapA activity. Cultures ( $n=3$ ) were harvested at $t=4 \mathrm{~h}$. GapA activity was measured in cell extracts. Cu treatment suppressed GapA activity in GSH-depleted cultures $(P=0.0007)$ but not in GSH-supplemented cultures $(P=0.51)$. (D) Expression of metal homeostasis genes. GSHsupplemented cultures $(n=3)$ were sampled at the indicated time points. Levels of copZ, cadD, adcAll, and siaA transcripts in Cu-treated cultures were determined by qPCR and normalized to the corresponding untreated samples that were harvested at the same time points. Horizontal dotted lines represent the limit of the assay $\left(\log _{2} \mathrm{FC}= \pm 0.5\right)$. Cu treatment induced copZ expression $(P=0.023,0.013,0.026$, and 0.093$)$, but not $\operatorname{cadD}(P=0.17,0.71,0.98$, and 0.32$)$, or adcAll $(P=0.39,0.50,0.03$, and 0.16$)$ at $t=2$, 3,4 , and $5 \mathrm{~h}$, respectively (versus $\left.\log _{2} \mathrm{FC}=0\right)$. Cu treatment continued to downregulate siaA expression $(P=0.63,0.03,0.04$, and 0.03 for $t=2,3,4$, and $5 \mathrm{~h}$, respectively, versus $\left.\log _{2} \mathrm{FC}=0\right)$. (E) Cu-dependent expression of copZ. Cultures $(n=3)$ were sampled at $t=4$ h. Levels of copZ transcripts in Cu-treated cultures were normalized to the corresponding untreated samples. Horizontal dotted lines represent the limit of the assay ( $\log _{2} \mathrm{FC}= \pm 0.5$ ). GSH supplementation did not affect copZ expression at low concentrations of added $\mathrm{Cu}$ (ns, $P=0.10,0.14,0.48,1.0$, and 0.31 for $[\mathrm{Cu}]=0,25,50,125$, and $500 \mathrm{nM}$ ), but it did affect expression at $1000 \mathrm{nM}$ added $\mathrm{Cu}(* * *$, $P=0.0009)$.

Notably, Cu treatment did not transcriptionally induce the uptake of GSH. Levels of gshT transcripts remained largely unchanged, based on RNA-seq analyses of $\Delta$ copA cells at the late-exponential phase of growth (Table 1). This result supports previous transcriptomic studies in several Gram-positive and Gram-negative bacteria, none of which identified GSH biosynthesis or uptake as a key transcriptional response to $\mathrm{Cu}$ treatment $(15,20,22,23)$.

Supplementation of the growth medium with GSH $(0.1 \mathrm{mM})$ did not affect the intracellular levels of this thiol at the early stages of growth ( $t=0$ and $2 \mathrm{~h}$; Fig. 6Bii). 
However, it did allow $\triangle \operatorname{cop} A$ cells to maintain intracellular concentrations of this tripeptide at $\sim 1 \mathrm{mM}$ (one log unit higher than unsupplemented cells) beyond the late exponential growth phase, regardless of Cu treatment (Fig. 6Bii). As mentioned earlier, these GSH-treated cells were Cu-tolerant (Fig. 5). In fact, these cells accumulated more intracellular $\mathrm{Cu}$ compared with the GSH-untreated control (Fig. 6A). The simplest explanation for this finding is that the rise in intracellular GSH levels leads to an increased ability to buffer intracellular $\mathrm{Cu}$. A more detailed examination of GSHsupplemented $\triangle \operatorname{copA}$ cells confirmed that GapA was protected from inactivation by added $\mathrm{Cu}$ (Fig. $6 \mathrm{C}$ ). In addition, the Cu-induced, time-dependent changes in cadD and adcAll expression were abolished (Fig. 6D), suggesting that CadC and AdcR did not become mismetalated. Some downregulation of siaA transcription was observed, albeit to a lesser magnitude compared with GSH-deplete cultures (Fig. 6D versus Fig. 4D). In general, these results support a model whereby GSH constitutes the major buffer for excess intracellular $\mathrm{Cu}$ in GAS and protects potential noncognate binding sites from becoming (mis)metalated by $\mathrm{Cu}$.

Importantly, GSH supplementation did not affect expression of copZ at low concentrations of added $\mathrm{Cu}(0$ to $500 \mathrm{nM}$; Fig. 6E). This observation further strengthens the proposal that GSH does not rescue the $\triangle \operatorname{copA}$ mutant simply by chelating extracellular $\mathrm{Cu}$ ions. However, GSH treatment did partially suppress copZ expression in response to a high concentration of added $\mathrm{Cu}(1,000 \mathrm{nM}$; Fig. 6E). This observation indicates the relative buffering strengths of GSH and CopY, which are discussed below.

\section{DISCUSSION}

Role of GSH in buffering excess cytoplasmic $\mathbf{C u}$. GSH has been proposed to bind $\mathrm{Cu}$ by assembling a stable, tetranuclear $\mathrm{Cu}_{4} \mathrm{GS}_{6}$ cluster (52). In such a model, when present at low millimolar concentrations (e.g., $\sim 4 \mathrm{mM}$ in GAS at $t=0$ h; Fig. $6 \mathrm{~A}$ ), GSH would bind $\mathrm{Cu}$ with an apparent affinity of $K_{D}=10^{-16.7} \mathrm{M}$ and thus would impose a threshold of $\mathrm{Cu}$ availability at $10^{-16.7} \mathrm{M}$ (see Fig. S7A). This threshold is above the range of $\mathrm{Cu}$ availability set by most bacterial Cu sensors (see Fig. S7B) (53-55). Therefore, GSH contributes to $\mathrm{Cu}$ buffering only when the transcriptionally responsive $\mathrm{Cu}$ homeostasis system is impaired (e.g., in a $\triangle c o p A$ mutant $[25,26]$ ) or overwhelmed (e.g., when intracellular $\mathrm{Cu}$ levels rise above the responsive range of the $\mathrm{Cu}$ sensors).

Figure 6 E shows that supplementation with GSH had little impact on metalation of CopY (and thus expression of copZ) when the amounts of added Cu were low. However, GSH appeared to dampen CopY response at higher concentrations of added $\mathrm{Cu}$, indicating that this thiol competes with $\mathrm{CopY}$ for binding $\mathrm{Cu}$ when intracellular $\mathrm{Cu}$ levels are high. Hence, the thresholds of intracellular Cu availability set by GSH and CopY may overlap, at least partially, with GSH being the weaker buffer $(52,55,56)$. The thermodynamic model in Fig. S7B is compatible with these experimental data, but it will need refinement. This model was estimated using known parameters (Cu affinity, DNA affinity, and number of DNA targets) for CopY from S. pneumoniae (CopY $\left.\mathrm{Spn}_{\mathrm{S}}\right)$ (55), but $\mathrm{CopY}_{\mathrm{Spn}}$ differs from $\mathrm{CopY}_{\mathrm{GAS}}$ in several key aspects. CopY $\mathrm{Spn}_{\mathrm{Sp}}$ lacks one of the two Cys-X-Cys motifs found in other CopY homologues such as CopY GAs and CopY from E. hirae $\left(\mathrm{CopY}_{\mathrm{Eh}}\right)$ (see Fig. S7D). CopY $\mathrm{Spn}_{\mathrm{Sp}}$ binds two $\mathrm{Cu}$ atoms per dimer in a solventexposed center while $\mathrm{COPY}_{\mathrm{Eh}}$ binds four $\mathrm{Cu}$ atoms per functional dimer and assembles a solvent-occluded center $(55,57)$. In addition, two cop boxes are present in $S$. pneumoniae (58), while only one is found in GAS. How these differences shift the threshold model will need to be examined using careful in vitro studies with purified proteins and DNA. In the simplest scenario, an increase in the stability (affinity) of the bound $\mathrm{Cu}$ atoms in CopY, which may occur as a consequence of coordination by extra Cys ligands, would lower the threshold of Cu availability set by CopY (see Fig. S7C) and thus better fit our experimental data.

Depletion of intracellular GSH to $0.1 \mathrm{mM}$ at the late exponential phase of growth would weaken its buffering capacity by at least 2 log units (see Fig. S7A). Figure 4 shows that $\mathrm{Cu}$ is then able to metalate nonspecific binding sites in non-cognate metallosensors or metalloenzymes. These results further suggest that AdcR, CadC, and MtsR can 


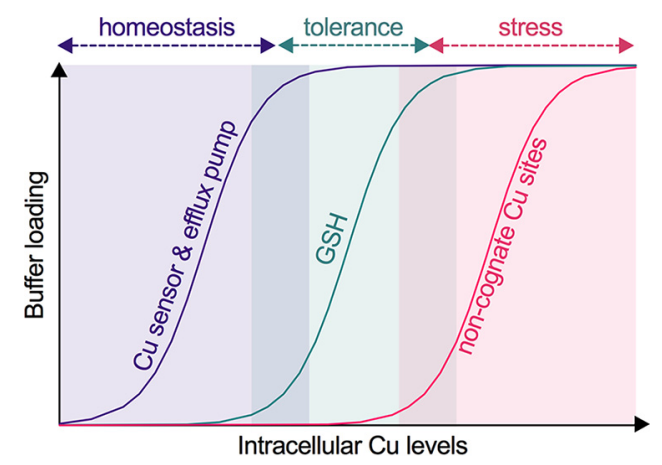

FIG 7 Threshold model for bacterial Cu homeostasis, tolerance, and stress. As Cu levels in the cytoplasm increase, this metal ion binds to the allosteric site of the Cu-sensing transcriptional regulator, which subsequently induces expression of the Cu efflux pump. Together, the Cu sensor and efflux pump impose a low limit of $\mathrm{Cu}$ availability and maintain $\mathrm{Cu}$ homeostasis. A further rise in cytoplasmic $\mathrm{Cu}$ levels saturates the $\mathrm{Cu}$ homeostasis system and begins to fill binding sites in GSH. Since there are no observable defects in bacterial metabolism or growth at this stage, GSH can be considered to confer Cu tolerance. GSH depletion or a further increase in cytoplasmic $\mathrm{Cu}$ levels saturates this tolerance capacity. Cu now binds to noncognate metal-binding sites, leading to inhibition of bacterial metabolism and growth. These conditions are considered as Cu stress.

allosterically respond to $\mathrm{Cu}$ and differentially regulate expression of their target genes in vivo. Precisely how this occurs will need to be confirmed with purified proteins and DNA in vitro. Cu-responsive regulation of genes under the control of non-cognate metallosensors has indeed been reported both in vivo and in vitro, although not for the families of regulators described here $(15,28,59-61)$.

Not all bacteria use GSH as the major cytoplasmic thiol. Some bacilli, such as $B$. subtilis and $\mathrm{S}$. aureus, produce the glycoside bacillithiol (BSH) instead. The affinity of BSH to $\mathrm{Cu}$ is at least 2 orders of magnitudes tighter than that of $\mathrm{GSH}(56,62)$. Hence, BSH likely imposes a lower limit on cytoplasmic $\mathrm{Cu}$ availability than does $\mathrm{GSH}$, but it is worth noting that its intracellular level is $\sim 30$ times lower than that of GSH (63). Importantly, the relative order with the endogenous $\mathrm{Cu}$ sensor $\mathrm{CsoR}$ still holds, with $\mathrm{BSH}$ binding $\mathrm{Cu}$ at least 3 log units more weakly than does CsoR (54). Indeed, this thiol is also thought to contribute to $\mathrm{Cu}$ homeostasis by buffering excess $\mathrm{Cu}$. Deletion of the $B$. subtilis bshC gene for BSH biosynthesis led to a slight increase in copZ expression in response to added $\mathrm{Cu}$. This result mirrors the finding in Fig. $6 \mathrm{E}$ and suggests that the $\mathrm{Cu}$ sensor $\mathrm{CsoR}$ is more readily metalated by $\mathrm{Cu}$ in the absence of the major buffering thiol (64). It is also notable that the identification of GapA as a major reservoir of excess $\mathrm{Cu}$ ions in the cytoplasm was in a strain of S. aureus that does not synthesize BSH (39).

In summary, this study provides a new line of evidence that $\mathrm{Cu}$ handling in the bacterial cytoplasm, when formulated using the threshold model, comprises two components (Fig. 7). The transcriptionally responsive component, which includes the Cu sensor, Cu efflux pump, and additional Cu-binding metallochaperones, functions in housekeeping or homeostasis and sets a low limit of $\mathrm{Cu}$ availability in the cytoplasm. Rising $\mathrm{Cu}$ levels can saturate this homeostasis system and sudden $\mathrm{Cu}$ shock can overwhelm it, but the transcriptionally unresponsive component, in this case GSH, buffers the excess $\mathrm{Cu}$ and confers additional $\mathrm{Cu}$ tolerance. This second system acts as the final layer of protection before cells experience widespread mismetalation and, therefore, Cu stress (Fig. 7). This additional buffering essentially extends the range of cytoplasmic $\mathrm{Cu}$ availability that can be tolerated by bacteria, allows bacteria to maintain key cellular functions, and thus prevents an abrupt transition from $\mathrm{Cu}$ homeostasis to $\mathrm{Cu}$ stress upon exposure to an excess of this metal ion. While this study focused exclusively on a Gram-positive bacterial organism, this concept is likely to apply to other bacterial systems and mammalian models (65).

Role of GSH in buffering bacterial Cu during host-pathogen interactions. This study was conducted originally to examine the role of the Cop Cu homeostasis system in GAS pathogenesis. Although GAS occupied a Cu-rich environment in mice (Fig. 1A), 
inactivation of the copA gene did not lead to a reduction in GAS virulence (Fig. 1C). Our in vitro investigations now suggest that GAS may withstand host-imposed increases in Cu levels, as long as it has access to a source of GSH in vivo. Indeed, GSH was detected in the skin ulcers of infected mice, but interestingly, the amount was $\sim 25$-fold less compared to skin from healthy mice or healthy skin from infected mice (see Fig. S8). Whether this depletion of GSH is a feature of the general host immune response, a consequence of inflammation and/or host tissue necrosis, or a consequence of GAS metabolism is not known. Nevertheless, the virulence of the $\triangle \operatorname{cop} A$ mutant implies that the level of host GSH, albeit reduced, can support $\mathrm{Cu}$ buffering inside the GAS cytoplasm. Alternatively, the level of host $\mathrm{Cu}$ (Fig. 1A) may not be sufficient to overwhelm the Cop homeostasis system, since the copYAZ operon was only slightly upregulated in bacteria isolated from mouse ulcers (average $\log _{2} \mathrm{FC}=1.13$ versus THY) (34).

Link between the failure to buffer $\mathrm{Cu}$ and redox stress. Under our experimental conditions, untreated $\triangle c o p A$ cells contained 17,000 to $23,000 \mathrm{Cu}$ atoms when sampled at $t=3 \mathrm{~h}$ (before the onset of Cu stress). Cu treatment increased this number to 78,000 to 330,000 atoms (see Fig. S4). The intracellular GSH concentrations at the same time point $\left([G S H]_{i}=0.76 \mathrm{mM}\right.$; Fig. $\left.6 \mathrm{~B}\right)$ would translate to $\sim 500,000$ molecules of $\mathrm{GSH}$, which are clearly insufficient to buffer all of the intracellular $\mathrm{Cu}$ ions. However, there was no observable $\mathrm{Cu}$ stress phenotype at this time point, suggesting that the excess $\mathrm{Cu}$ is also bound to other cytoplasmic component(s). These components may include CopZ and/or the novel, uncharacterized protein CopX (see Fig. S1A). This idea will be the focus of future studies.

Finally, the GSH/GSSG couple is the major redox buffer of the cell. Assuming that the GSH/GSSG ratio remains unchanged, depletion of intracellular GSH in GAS from $\sim 4$ to $\sim 0.1 \mathrm{mM}$ would raise the cytoplasmic redox midpotential by $\sim 46 \mathrm{mV}$. This relatively more oxidizing environment, when combined with a lack of Cu buffering, may promote the Cu-catalyzed generation of reactive oxygen species (66) or the formation of disulfides (67). Yet, our RNA-seq results do not suggest widespread oxidative stress (see Data Set S1). In E. coli, deletion of gshA did not accelerate DNA damage in Cu-replete cells, even in the presence of added $\mathrm{H}_{2} \mathrm{O}_{2}$ (68). Similarly, proteomic analyses of a non-BSH-producing strain of $\mathrm{S}$. aureus indicated that $\mathrm{Cu}$ treatment does not induce a strong oxidative stress response in this organism (39).

Regardless of the relative importance of mismetalation versus redox stress, our work demonstrates that excess $\mathrm{Cu}$ is not bacteriotoxic as long as cytoplasmic GSH is abundant and thus able to buffer the excess of this metal ion (Fig. 7). In GAS, a GSH auxotroph, this intracellular buffer is dynamic; its levels change during bacterial growth and/or in response to extracellular GSH availability. Future studies should take these effects into account when examining the impact of $\mathrm{Cu}$ treatment on bacterial cultures. Had our work not identified the 4-h time point as metabolically relevant, sampling cultures $1 \mathrm{~h}$ earlier would have led to a different conclusion.

\section{MATERIALS AND METHODS}

Data presentation and statistical analyses. We follow recent recommendations regarding transparency in data representation $(69,70)$. Except for growth curves, individual data points from independent experiments are plotted, with shaded columns representing the means and error bars representing standard deviations. Growth curves show the means of independent experiments, with shaded regions representing standard deviations. The number of independent experiments is stated clearly in each figure legend. Statistical analyses have been performed on all numerical data, but notations of statistical significance are displayed on plots only if they aid in rapid, visual interpretation. Otherwise, $P$ values for key comparisons are stated in the figure legends. Unless otherwise stated, statistical tests used two-way analysis of variance using the statistical package in GraphPad Prism 8.0. All analyses were corrected for multiple comparisons.

Ethics statement. Animal experiments were conducted according to the Guidelines for the Care and Use of Laboratory Animals (National Health and Medical Research Council, Australia) and were approved by the University of Queensland Animal Ethics Committee (Australia). Human blood donation for use in neutrophil killing studies was conducted in accordance with the National Statement on Ethical Conduct in Human Research and in compliance with the regulations governing experimentation on humans, and was approved by the University of Queensland Medical Research Ethics Committee (Australia). 
Reagents. All reagents were of analytical grade and obtained from Sigma or Melford Chemicals unless otherwise indicated. $\gamma$-Glu-Cys and Cys-Gly were from BACHEM Peptides (Germany). The sulfate and chloride salts of copper were used interchangeably. All reagents were prepared in deionized water.

Strains and culture conditions. GAS M1T1 5448 strains were propagated from frozen glycerol stocks onto solid THY medium without any antibiotics. Unless otherwise indicated, liquid cultures were prepared in a chemically defined medium containing glucose as the carbon source (CDM-glucose; see Data Set S2A). This medium routinely contained $53 \mathrm{nM}$ basal $\mathrm{Cu}, 155 \mathrm{nM} \mathrm{Zn}, 66 \mathrm{nM}$ Fe, $9 \mathrm{nM} \mathrm{Mn}, 29 \mathrm{nM}$ Co, and $23 \mathrm{nM} \mathrm{Ni}$, as determined by inductively coupled plasma mass spectrometry (ICP-MS). All solid and liquid growth media contained catalase $(50 \mu \mathrm{g} / \mathrm{ml})$.

Construction of mutants. Nonpolar GAS mutant strains were constructed by allelic exchange following standard protocols (71). Primers and plasmids used in this study are listed in Data Set S2B. All constructs and genetically altered strains were confirmed by PCR and Sanger sequencing.

Mice virulence assays. Transgenic, human plasminogenized AlbPLG1 mice heterozygous for the human transgene were backcrossed greater than $n=6$ with C57BL/J6 mice as described previously (72). GAS was prepared to obtain the target dose in the $10^{7}$ CFU range (WT, $1.8 \times 10^{7} ; \Delta \operatorname{cop} A, 1.5 \times 10^{7}$ ) immediately prior to injection. Mice were subcutaneously infected $(n=10)$, and virulence was determined by observing survival for 10 days post-infection. Metal levels in mouse blood and skin were measured by ICP-MS as described previously (73).

To assess GSH levels at the site of infection, mouse skin and infected lesions were excised 3 days post-infection, washed with phosphate-buffered saline (PBS), resuspended in $1 \mathrm{ml}$ of PBS, homogenized in Lysing Matrix F tubes using a FastPrep 24G instrument (MP Biomedicals; $4^{\circ} \mathrm{C}$, speed 6, $40 \mathrm{~s}, 2$ cycles), and centrifuged $\left(10,000 \times g, 5 \mathrm{~min}, 4^{\circ} \mathrm{C}\right)$. Total GSH was measured from the supernatant using the GSH-Glo kit (Promega) according to the manufacturer's instructions, with the modification of mixing undiluted samples 1:1 with $2 \mathrm{mM}$ Tris(2-carboxyethyl)phosphine (TCEP) immediately prior to use.

Neutrophil-killing assays. Survival of GAS after incubation with human neutrophils ex vivo was assayed at a multiplicity of infection of 10:1 as previously described (72).

Bacterial growth. Growth was assessed at $37^{\circ} \mathrm{C}$ in flat-bottomed 96 -well plates using an automated microplate shaker and reader. Each well contained $200 \mu \mathrm{l}$ of culture. Each plate was sealed with a gas permeable, optically clear membrane (Diversified Biotech). $\mathrm{OD}_{600}$ values were measured every 20 min for $12 \mathrm{~h}$. The plates were shaken at $200 \mathrm{rpm}$ for $1 \mathrm{~min}$ in the double orbital mode immediately before each reading. $\mathrm{OD}_{600}$ values were not corrected for path length (ca. $0.58 \mathrm{~cm}$ for a $200-\mu$ l culture).

Plating efficiency. GAS was cultured in 96-well plates as described earlier for growth analysis, sampled at the indicated time points, vortexed for $30 \mathrm{~s}$, diluted serially in PBS, and plated onto solid THY medium without any antibiotics. Colonies were enumerated after overnight incubation at $37^{\circ} \mathrm{C}$.

ATP levels. GAS was cultured in 96-well plates as described earlier for growth analysis and sampled at the indicated time points. The amount of total ATP in each sample was determined immediately using the BacTiter-Glo kit (Promega).

Intracellular metal content. GAS was cultured in 10 to $500 \mathrm{ml}$ of CDM-glucose as required (larger volumes were required to obtain enough biomass at earlier time points). At the desired time points, an aliquot was collected for the measurement of $\mathrm{OD}_{600}$ or plating efficiency. The remaining cultures were harvested $\left(5,000 \times g, 4^{\circ} \mathrm{C}, 10 \mathrm{~min}\right)$ and then washed once with PBS containing EDTA ( $\left.1 \mathrm{mM}\right)$ and twice with ice-cold PBS. The final pellet was dissolved in concentrated nitric acid $\left(150 \mu \mathrm{l}, 80^{\circ} \mathrm{C}, 1 \mathrm{~h}\right)$ and diluted to $10 \mathrm{ml}$ with deionized water. Total metal levels were determined by ICP-MS. The results were normalized to $\mathrm{OD}_{600}$ values or plating efficiency as indicated in the figure legends.

Fermentation end products. GAS was cultured in 96-well plates as described earlier for growth analysis. At the desired time points, samples were centrifuged $\left(5,000 \times \mathrm{g}, 4^{\circ} \mathrm{C}, 10 \mathrm{~min}\right)$ and the supernatants were frozen at $-20^{\circ} \mathrm{C}$ until further use. Concentrations of pyruvate, lactate, acetate, and ethanol in the spent culture media were determined by using K-PYRUV, K-LATE, K-ACET, and K-ETOH kits (Megazyme), respectively. Concentrations of glucose were determined using the GAGO20 kit (Sigma).

Enzyme activity. GAS was cultured in 40 to $250 \mathrm{ml}$ of CDM-glucose as required (larger volumes were required to obtain enough biomass at earlier time points). At the desired time points, bacteria were harvested $\left(5,000 \times g, 4^{\circ} \mathrm{C}, 10 \mathrm{~min}\right)$, washed once with PBS, and frozen at $-20^{\circ} \mathrm{C}$ until further use. Bacterial pellets were resuspended in a buffer containing sodium phosphate $(100 \mathrm{mM})$ and triethanolamine $(80 \mathrm{mM})$ at $\mathrm{pH} 7.4$, transferred to a tube containing Lysing Matrix B (MP Biomedicals), and lysed in a FastPrep 24G instrument (MP Biomedicals, $10 \mathrm{~m} / \mathrm{s}, 20 \mathrm{~s}, 2$ cycles). Cell debris were removed by centrifugation $(20,000 \times g, 1 \mathrm{~min})$. The cell-free lysate supernatant was kept on ice and used immediately.

To determine GapA activity, the reaction mixture contained NAD $\mathrm{NA}^{+}(4 \mathrm{mM})$, DL-glyceraldehyde-3phosphate (G3P; $0.3 \mathrm{mg} / \mathrm{ml})$, sodium phosphate $(100 \mathrm{mM})$, dithiothreitol $(1 \mathrm{mM})$, and triethanolamine $(80 \mathrm{mM})$ at $\mathrm{pH}$ 7.4. GapN activity was determined as described above for GapA but using NADP+ $(4 \mathrm{mM})$ instead of $\mathrm{NAD}^{+}$as the electron acceptor. To measure the activity of Ldh, the reaction mixture contained $\mathrm{NADH}(4 \mathrm{mM})$, pyruvate $(10 \mathrm{mM})$, and fructose-1,6-bisphosphate $(1 \mathrm{mM})$ in PBS at $\mathrm{pH}$ 7.4. For all three enzymes, each reaction $(100 \mu \mathrm{l})$ was initiated by addition of cell extracts $(10 \mu \mathrm{l})$. Absorbance values at $340 \mathrm{~nm}$ were monitored for up to $10 \mathrm{~min}$ at $37^{\circ} \mathrm{C}$. The initial rates of reaction were normalized to total protein content as determined using the QuantiPro BCA assay kit (Sigma). Control reactions without any substrate (G3P for GapA and GapN, pyruvate for Ldh) were always performed in parallel.

One unit of activity was defined as follows: 1,000 nmol NAD ${ }^{+}$oxidized $\mathrm{min}^{-1} \mathrm{mg}$ protein ${ }^{-1}$ for GapA, $100 \mathrm{nmol} \mathrm{NADP}{ }^{+}$oxidized $\mathrm{min}^{-1} \mathrm{mg} \mathrm{protein}^{-1}$ for GapN, and 1,000 $\mathrm{mmol} \mathrm{NADH}$ reduced $\mathrm{min}^{-1} \mathrm{mg}$ protein $^{-1}$ for Ldh. 
GSH levels. GAS was cultured in 10 to $150 \mathrm{ml}$ of CDM-glucose as required (larger volumes were required to obtain enough biomass at earlier time points). At the desired time points, an aliquot was plated for bacterial counting. The remaining cultures were harvested $\left(5,000 \times g, 4^{\circ} \mathrm{C}, 10 \mathrm{~min}\right)$, washed twice with PBS, resuspended in 5-sulfosalycylic acid (5 wt/vol \%), transferred to a tube containing Lysing Matrix $\mathrm{B}$, and frozen at $-20^{\circ} \mathrm{C}$ until further use. Bacteria were lysed in a bead beater $(10 \mathrm{~m} / \mathrm{s}, 30 \mathrm{~s}, 2 \mathrm{cycles})$. Cell debris were removed by centrifugation $(20,000 \times g, 1 \mathrm{~min})$. Total GSH (and GSSG) levels in lysate supernatants were determined immediately using the Gor-DTNB recycling method (74) and normalized to total bacterial counts.

RNA extraction. GAS was cultured in 2 to $200 \mathrm{ml}$ of CDM-glucose as required (larger volumes were required to obtain enough biomass at earlier time points). At the desired time points, cultures were centrifuged $\left(3,000 \times g, 4^{\circ} \mathrm{C}, 5 \mathrm{~min}\right)$. Bacterial pellets were resuspended immediately in $1 \mathrm{ml}$ of RNAPro solution (MP Biomedicals) and stored at $-80^{\circ} \mathrm{C}$ until further use. Bacteria were lysed in Lysing Matrix $B$, and total RNA was extracted according to the manufacturer's protocol (MP Biomedicals). RNA extracts were treated with RNase-Free DNase I enzyme (New England Biolabs). Complete removal of gDNA was confirmed by PCR using gapA-check-F/R primers (see Data Set S2B). gDNA-free RNA was purified by using an RNeasy minikit (Qiagen) and visualized on an agarose gel.

qPCR analyses. CDNA was generated from $1 \mu \mathrm{g}$ of RNA using the SuperScript IV first-strand synthesis system (Invitrogen). qPCR was performed in 10- or 20- $\mu$ l reactions using 2 or $5 \mathrm{ng}$ of cDNA as the template and $0.4 \mu \mathrm{M}$ concentrations of the appropriate primer pairs (see Data Set $2 \mathrm{~B}$ ). Each sample was analyzed in technical duplicates. Amplicons were detected with PowerUP SYBR green (Invitrogen) in a QuantStudio 6 Flex real-time PCR system (Applied Biosystems) or a CFXConnect Real-Time PCR Instrument (Bio-Rad Laboratories). $C_{q}$ values were calculated using LinRegPCR after correcting for amplicon efficiency. $C_{q}$ values of technical duplicates were typically within \pm 0.25 of each other.holB and tufA, which encode DNA polymerase III and elongation factor Tu, respectively, were used as reference genes (see Data Set S2B). Their transcription levels remained constant in all of the experimental conditions tested here. hol $B$ was used as the reference gene in all the data presented here because its $C_{q}$ values were closer to the dynamic ranges of cop genes, adcAll, cadD, and siaA, but the results were identical with when tufA was used as the reference.

RNA-seq analyses. GAS $\triangle$ copA mutant strain was cultured in the presence of 0 or $5 \mu \mathrm{M}$ added $\mathrm{Cu}$ for $t=5 \mathrm{~h}(n=3)$, and RNA was extracted from each culture as described earlier. RNA-seq was performed from Ribo-zero (rRNA-depleted) triplicate samples on a single Illumina HiSeq 2500 lane using v4 chemistry from 75-bp paired-end reads. Reads were mapped to the 5448 (M1) GAS reference genome (GenBank accession number CP008776.1) with BWA MEM (v0.7.16). Relative read counts (per gene) and differential gene expression was determined using DESeq2 (v1.26.0) (75) in R. Genes with fewer than 10 reads across all conditions and samples were removed. $P$ values were calculated using Wald test and adjusted for multiple testing using the Benjamini-Hochberg method for controlling the false discovery rate. Illumina read data were deposited in the European Nucleotide Archive Sequence Read Archive under accession numbers ERS1996831, ERS1996835, and ERS1996839.

\section{SUPPLEMENTAL MATERIAL}

Supplemental material is available online only.

DATA SET S1, XLSX file, $0.02 \mathrm{MB}$.

DATA SET S2, XLSX file, $0.02 \mathrm{MB}$.

FIG S1, TIF file, $0.8 \mathrm{MB}$.

FIG S2, TIF file, 1 MB.

FIG S3, TIF file, $1.5 \mathrm{MB}$.

FIG S4, TIF file, $0.3 \mathrm{MB}$.

FIG S5, TIF file, 1.3 MB.

FIG S6, TIF file, $0.8 \mathrm{MB}$

FIG S7, TIF file, $1.8 \mathrm{MB}$

FIG S8, TIF file, $0.1 \mathrm{MB}$.

\section{ACKNOWLEDGMENTS}

We thank Peter Chivers and members of the Metals in Biology group (Department of Biosciences, Durham University) for helpful discussions related to this project and Robert Borthwick (Department of Physics, Durham University) for reviewing the manuscript. Marietjie Mostert (School of Earth Sciences, The University of Queensland) and Deenah Morton (Department of Biosciences, Durham University) provided technical assistance with ICP-MS. Amanda Walker and Nadia Keller (School of Chemistry and Molecular Biosciences, The University of Queensland) assisted with collection of mice tissues. Ian Cummins (Department of Biosciences, Durham University) provided technical assistance with measurements of growth media components using mass spectrometry. The assistance of the sequencing and pathogen informatics core teams at the Wellcome Trust Sanger Institute is also acknowledged. 
L.J.S. was funded by a Wellcome Trust Seed Award (214930/Z/18/Z) to KYD. C.-L.Y.O. was supported by a Garnett Passe and Rodney Williams Memorial Foundation Research Fellowship. Preliminary work leading to this study was financially supported by a Royal Society Research grant (RSG\R1\180044) and Department of Biosciences (Durham University) start-up funds to K.Y.D. RNA sequencing was supported by the Wellcome Trust through the Wellcome Trust Sanger Institute. K.J.W. was supported by a grant from the Biotechnology and Biological Sciences Research Council (BB/S006818/1). This research was also supported by grants from the National Health and Medical Research Council of Australia to A.G.M., M.J.W., and M.R.D.

A.G.M., K.J.W., K.Y.D., and M.J.W. initiated the research. K.Y.D. had overall responsibility for the conceptualization and coordination of the program. K.Y.D. designed the experiments with input from K.J.W. C.-L.Y.O. and M.M.Z. generated the $\triangle c 0 p A$ and $\mathrm{copA}^{+}$mutant strains. K.Y.D. and L.J.S. conducted the in vitro experiments. C.-L.Y.O. and M.M.Z. performed infection assays in neutrophils. C.-L.Y.O., M.Z., and S.B. performed mice infection assays. M.R.D. and L.M. conducted the RNA-seq analyses. All authors contributed to data analysis. K.J.W., K.Y.D., and L.J.S. wrote the initial manuscript. All authors reviewed and approved the final version of the manuscript.

\section{REFERENCES}

1. Poole K. 2017. At the nexus of antibiotics and metals: the impact of $\mathrm{Cu}$ and $\mathrm{Zn}$ on antibiotic activity and resistance. Trends Microbiol 25 820-832. https://doi.org/10.1016/j.tim.2017.04.010.

2. Hao X, Lüthje F, Rønn R, German NA, Li X, Huang F, Kisaka J, Huffman D, Alwathnani HA, Zhu Y-G, Rensing C. 2016. A role for copper in protozoan grazing: two billion years selecting for bacterial copper resistance. Mol Microbiol 102:628-641. https://doi.org/10.1111/mmi.13483.

3. White C, Lee J, Kambe T, Fritsche K, Petris MJ. 2009. A role for the ATP7A copper-transporting ATPase in macrophage bactericidal activity. J Biol Chem 284:33949-33956. https://doi.org/10.1074/jbc.M109.070201.

4. Achard MES, Stafford SL, Bokil NJ, Chartres J, Bernhardt PV, Schembri MA, Sweet MJ, McEwan AG. 2012. Copper redistribution in murine macrophages in response to Salmonella infection. Biochem J 444:51-57. https://doi.org/10.1042/BJ20112180.

5. Culbertson EM, Khan AA, Muchenditsi A, Lutsenko S, Sullivan DJ, Petris MJ, Cormack BP, Culotta VC. 2020. Changes in mammalian copper homeostasis during microbial infection. Metallomics 12:416-426. https://doi.org/10.1039/c9mt00294d.

6. Shen Q, Beucler MJ, Ray SC, Rappleye CA. 2018. Macrophage activation by IFN- $\gamma$ triggers restriction of phagosomal copper from intracellular pathogens. PLoS Pathog 14:e1007444. https://doi.org/10.1371/journal .ppat.1007444.

7. Wolschendorf F, Ackart D, Shrestha TB, Hascall-Dove L, Nolan S, Lamichhane G, Wang Y, Bossmann SH, Basaraba RJ, Niederweis M. 2011. Copper resistance is essential for virulence of Mycobacterium tuberculosis. Proc Natl Acad Sci U S A 108:1621-1626. https://doi.org/ 10.1073/pnas.1009261108.

8. Hyre AN, Kavanagh K, Kock ND, Donati GL, Subashchandrabose S. 2017. Copper is a host effector mobilized to urine during urinary tract infection to impair bacterial colonization. Infect Immun 85:e01041-16. https://doi .org/10.1128/IAI.01041-16.

9. Subashchandrabose $S$, Hazen TH, Brumbaugh AR, Himpsl SD, Smith SN, Ernst RD, Rasko DA, Mobley HLT. 2014. Host-specific induction of Escherichia coli fitness genes during human urinary tract infection. Proc Natl Acad Sci U S A 111:18327-18332. https://doi.org/10.1073/ pnas.1415959112.

10. Djoko KY, Ong CY, Walker MJ, McEwan AG. 2015. The role of copper and zinc toxicity in innate immune defense against bacterial pathogens. J Biol Chem 290:18954-18961. https://doi.org/10.1074/jbc.R115.647099.

11. Foster AW, Osman D, Robinson NJ. 2014. Metal preferences and metallation. J Biol Chem 289:28095-28103. https://doi.org/10.1074/jbc.R114 .588145 .

12. Argüello JM, Raimunda D, Padilla-Benavides T. 2013. Mechanisms of copper homeostasis in bacteria. Front Cell Infect Microbiol 3:73. https:// doi.org/10.3389/fcimb.2013.00073.

13. Macomber L, Imlay JA. 2009. The iron-sulfur clusters of dehydratases are primary intracellular targets of copper toxicity. Proc Natl Acad Sci U S A 106:8344-8349. https://doi.org/10.1073/pnas.0812808106.

14. Azzouzi A, Steunou A-S, Durand A, Khalfaoui-Hassani B, Bourbon M-L, Astier C, Bollivar DW, Ouchane S. 2013. Coproporphyrin III excretion identifies the anaerobic coproporphyrinogen III oxidase $\mathrm{HemN}$ as a copper target in the $\mathrm{Cu}^{+}$-ATPase mutant $\operatorname{copA}^{-}$of Rubrivivax gelatinosus. Mol Microbiol 88:339-351. https://doi.org/10.1111/mmi.12188.

15. Johnson MDL, Kehl-Fie TE, Rosch JW. 2015. Copper intoxication inhibits aerobic nucleotide synthesis in Streptococcus pneumoniae. Metallomics 7:786-794. https://doi.org/10.1039/c5mt00011d.

16. Djoko KY, Phan M-D, Peters KM, Walker MJ, Schembri MA, McEwan AG. 2017. Interplay between tolerance mechanisms to copper and acid stress in Escherichia coli. Proc Natl Acad Sci U S A 114:6818-6823. https://doi.org/10.1073/pnas.1620232114.

17. Gold B, Deng H, Bryk R, Vargas D, Eliezer D, Roberts J, Jiang X, Nathan C. 2008. Identification of a copper-binding metallothionein in pathogenic mycobacteria. Nat Chem Biol 4:609-616. https://doi.org/10 .1038/nchembio.109.

18. Straw ML, Chaplin AK, Hough MA, Paps J, Bavro VN, Wilson MT, Vijgenboom E, Worrall JAR. 2018. A cytosolic copper storage protein provides a second level of copper tolerance in Streptomyces lividans. Metallomics 10:180-193. https://doi.org/10.1039/c7mt00299h.

19. Corbett D, Schuler S, Glenn S, Andrew PW, Cavet JS, Roberts IS. 2011. The combined actions of the copper-responsive repressor CsoR and coppermetallochaperone CopZ modulate CopA-mediated copper efflux in the intracellular pathogen Listeria monocytogenes. Mol Microbiol 81: 457-472. https://doi.org/10.1111/j.1365-2958.2011.07705.x.

20. Quintana J, Novoa-Aponte L, Argüello JM. 2017. Copper homeostasis networks in the bacterium Pseudomonas aeruginosa. J Biol Chem 292: 15691-15704. https://doi.org/10.1074/jbc.M117.804492.

21. Braymer JJ, Giedroc DP. 2014. Recent developments in copper and zinc homeostasis in bacterial pathogens. Curr Opin Chem Biol 19:59-66. https://doi.org/10.1016/j.cbpa.2013.12.021.

22. Kershaw CJ, Brown NL, Constantinidou C, Patel MD, Hobman JL. 2005. The expression profile of Escherichia coli $\mathrm{K}-12$ in response to minimal, optimal, and excess copper concentrations. Microbiology 151: 1187-1198. https://doi.org/10.1099/mic.0.27650-0.

23. Yamamoto K, Ishihama A. 2005. Transcriptional response of Escherichia coli to external copper. Mol Microbiol 56:215-227. https://doi.org/10 .1111/j.1365-2958.2005.04532.x.

24. Potter AJ, Trappetti C, Paton JC. 2012. Streptococcus pneumoniae uses glutathione to defend against oxidative stress and metal ion toxicity. J Bacteriol 194:6248-6254. https://doi.org/10.1128/JB.01393-12.

25. Grosse C, Schleuder G, Schmole C, Nies DH. 2014. Survival of Escherichia coli cells on solid copper surfaces is increased by glutathione. Appl Environ Microbiol 80:7071-7078. https://doi.org/10.1128/AEM.02842-14. 26. Helbig K, Bleuel C, Krauss GJ, Nies DH. 2008. Glutathione and transition- 
metal homeostasis in Escherichia coli. J Bacteriol 190:5431-5438. https:// doi.org/10.1128/JB.00271-08.

27. Tottey S, Patterson CJ, Banci L, Bertini I, Felli IC, Pavelkova A, Dainty SJ, Pernil R, Waldron KJ, Foster AW, Robinson NJ. 2012. Cyanobacterial metallochaperone inhibits deleterious side reactions of copper. Proc Natl Acad Sci U S A 109:95-100. https://doi.org/10.1073/pnas .1117515109.

28. Dainty SJ, Patterson CJ, Waldron KJ, Robinson NJ. 2010. Interaction between cyanobacterial copper chaperone Atx 1 and zinc homeostasis. J Biol Inorg Chem 15:77-85. https://doi.org/10.1007/s00775-009-0555-z.

29. Young CA, Gordon LD, Fang Z, Holder RC, Reid SD. 2015. Copper tolerance and characterization of a copper-responsive operon, copYAZ, in an M1T1 clinical strain of Streptococcus pyogenes. J Bacteriol 197: 2580-2592. https://doi.org/10.1128/JB.00127-15.

30. Alquethamy SF, Khorvash M, Pederick VG, Whittall JJ, Paton JC, Paulsen IT, Hassan KA, McDevitt CA, Eijkelkamp BA. 2019. The role of the CopA copper efflux system in Acinetobacter baumannii virulence. Int J Mol Sci 20:575. https://doi.org/10.3390/ijms20030575.

31. Shafeeq S, Yesilkaya H, Kloosterman TG, Narayanan G, Wandel M, Andrew PW, Kuipers OP, Morrissey JA. 2011. The cop operon is required for copper homeostasis and contributes to virulence in Streptococcus pneumoniae. Mol Microbiol 81:1255-1270. https://doi.org/10.1111/j.1365 -2958.2011.07758.x

32. Johnson MDL, Kehl-Fie TE, Klein R, Kelly J, Burnham C, Mann B, Rosch JW. 2015. Role of copper efflux in pneumococcal pathogenesis and resistance to macrophage-mediated immune clearance. Infect Immun 83: 1684-1694. https://doi.org/10.1128/IAI.03015-14.

33. Sun H, Ringdahl U, Homeister JW, Fay WP, Engleberg NC, Yang AY, Rozek LS, Wang X, Sjöbring U, Ginsburg D. 2004. Plasminogen is a critical host pathogenicity factor for group A streptococcal infection. Science 305: 1283-1286. https://doi.org/10.1126/science.1101245.

34. Hirose $Y$, Yamaguchi M, Okuzaki D, Motooka D, Hamamoto H, Hanada T, Sumitomo T, Nakata M, Kawabata S. 2019. Streptococcus pyogenes transcriptome changes in the inflammatory environment of necrotizing fasciitis. Appl Environ Microbiol 85:e01428-19. https://doi.org/10.1128/ AEM.01428-19.

35. Watson ME, Neely MN. 2016. Animal models of Streptococcus pyogenes infection. In Streptococcus pyogenes: basic biology to clinical manifestations. Oklahoma Health Sciences Center, Oklahoma City, OK.

36. Le Breton Y, Mistry P, Valdes KM, Quigley J, Kumar N, Tettelin H, Mclver KS. 2013. Genome-wide identification of genes required for fitness of group A Streptococcus in human blood. Infect Immun 81:862-875. https://doi.org/10.1128/IAI.00837-12.

37. Breton YL, Belew AT, Freiberg JA, Sundar GS, Islam E, Lieberman J, Shirtliff ME, Tettelin H, El-Sayed NM, Mclver KS. 2017. Genome-wide discovery of novel M1T1 group A streptococcal determinants important for fitness and virulence during soft-tissue infection. PLoS Pathog 13: e1006584. https://doi.org/10.1371/journal.ppat.1006584.

38. Wang H, Wang M, Yang X, Xu X, Hao Q, Yan A, Hu M, Lobinski R, Li H, Sun H. 2019. Antimicrobial silver targets glyceraldehyde-3-phosphate dehydrogenase in glycolysis of Escherichia coli. Chem Sci 10:7193-7199. https://doi.org/10.1039/c9sc02032b.

39. Tarrant E, Riboldi GP, Mcllvin MR, Stevenson J, Barwinska-Sendra A, Stewart LJ, Saito MA, Waldron KJ. 2019. Copper stress in Staphylococcus aureus leads to adaptive changes in central carbon metabolism. Metallomics 11:183-200. https://doi.org/10.1039/c8mt00239h.

40. Takahashi S, Abbe K, Yamada T. 1982. Purification of pyruvate formatelyase from Streptococcus mutans and its regulatory properties. J Bacteriol 149:1034-1040. https://doi.org/10.1128/JB.149.3.1034-1040.1982.

41. Brückner R, Titgemeyer F. 2002. Carbon catabolite repression in bacteria: choice of the carbon source and autoregulatory limitation of sugar utilization. FEMS Microbiol Lett 209:141-148. https://doi.org/10.1111/j 1574-6968.2002.tb11123.x.

42. Ye JJ, Saier MH. 1996. Regulation of sugar uptake via the phosphoenolpyruvate-dependent phosphotransferase systems in Bacillus subtilis and Lactococcus lactis is mediated by ATP-dependent phosphorylation of seryl residue 46 in HPr. J Bacteriol 178:3557-3563. https://doi .org/10.1128/jb.178.12.3557-3563.1996.

43. Sanson M, Makthal N, Flores AR, Olsen RJ, Musser JM, Kumaraswami M. 2015. Adhesin competence repressor (AdcR) from Streptococcus pyogenes controls adaptive responses to zinc limitation and contributes to virulence. Nucleic Acids Res 43:418-432. https://doi.org/10.1093/nar/ gku1304.

44. Do H, Makthal N, Chandrangsu P, Olsen RJ, Helmann JD, Musser JM,
Kumaraswami M. 2019. Metal sensing and regulation of adaptive responses to manganese limitation by MtsR is critical for group A streptococcus virulence. Nucleic Acids Res 47:7476-7493. https://doi.org/10 .1093/nar/gkz524.

45. Ye J, Kandegedara A, Martin P, Rosen BP. 2005. Crystal structure of the Staphylococcus aureus pl258 CadC Cd(II)/Pb(II)/Zn(II)-responsive repressor. J Bacteriol 187:4214-4221. https://doi.org/10.1128/JB.187.12.4214 $-4221.2005$.

46. Ong CY, Gillen CM, Barnett TC, Walker MJ, McEwan AG. 2014. An antimicrobial role for zinc in innate immune defense against group A Streptococcus. J Infect Dis 209:1500-1508. https://doi.org/10.1093/infdis/ jiu053.

47. Dennison C, David S, Lee J. 2018. Bacterial copper storage proteins. J Biol Chem 293:4616-4627. https://doi.org/10.1074/jbc.TM117.000180.

48. Fung DKC, Lau WY, Chan WT, Yan A. 2013. Copper efflux is induced during anaerobic amino acid limitation in Escherichia coli to protect iron-sulfur cluster enzymes and biogenesis. J Bacteriol 195:4556-4568. https://doi.org/10.1128/JB.00543-13.

49. Gopal S, Borovok I, Ofer A, Yanku M, Cohen G, Goebel W, Kreft J, Aharonowitz Y. 2005. A multidomain fusion protein in Listeria monocytogenes catalyzes the two primary activities for glutathione biosynthesis. J Bacteriol 187:3839-3847. https://doi.org/10.1128/JB.187.11.3839-3847.2005.

50. Vergauwen B, Verstraete K, Senadheera DB, Dansercoer A, Cvitkovitch DG, Guédon E, Savvides SN. 2013. Molecular and structural basis of glutathione import in Gram-positive bacteria via GshT and the cystine ABC importer TcyBC of Streptococcus mutans. Mol Microbiol 89:288-303. https://doi.org/10.1111/mmi.12274.

51. Sherrill C, Fahey RC. 1998. Import and metabolism of glutathione by Streptococcus mutans. J Bacteriol 180:1454-1459. https://doi.org/10 .1128/JB.180.6.1454-1459.1998.

52. Morgan MT, Nguyen LAH, Hancock HL, Fahrni CJ. 2017. Glutathione limits aquacopper(I) to sub-femtomolar concentrations through cooperative assembly of a tetranuclear cluster. J Biol Chem 292:21558-21567. https://doi.org/10.1074/jbc.M117.817452.

53. Osman D, Martini MA, Foster AW, Chen J, Scott AJP, Morton RJ, Steed JW, Lurie-Luke E, Huggins TG, Lawrence AD, Deery E, Warren MJ, Chivers PT, Robinson NJ. 2019. Bacterial sensors define intracellular free energies for correct enzyme metallation. Nat Chem Biol 15:241-249. https://doi.org/ 10.1038/s41589-018-0211-4.

54. Ma Z, Cowart DM, Scott RA, Giedroc DP. 2009. Molecular insights into the metal selectivity of the $\mathrm{Cu}(\mathrm{I})$-sensing repressor $\mathrm{CsoR}$ from Bacillus subtilis. Biochemistry 48:3325-3334. https://doi.org/10.1021/bi900115w.

55. Glauninger $\mathrm{H}$, Zhang $\mathrm{Y}$, Higgins $\mathrm{KA}$, Jacobs AD, Martin JE, Fu Y, Coyne Rd HJ, Bruce KE, Maroney MJ, Clemmer DE, Capdevila DA, Giedroc DP. 2018. Metal-dependent allosteric activation and inhibition on the same molecular scaffold: the copper sensor CopY from Streptococcus pneumoniae. Chem Sci 9:105-118. https://doi.org/10.1039/c7sc04396a.

56. Xiao Z, Brose J, Schimo S, Ackland SM, La Fontaine S, Wedd AG. 2011. Unification of the copper(I) binding affinities of the metallo-chaperones Atx1, Atox1, and related proteins. J Biol Chem 286:11047-11055. https:// doi.org/10.1074/jbc.M110.213074.

57. Cobine P, Wickramasinghe WA, Harrison MD, Weber T, Solioz M, Dameron CT. 1999. The Enterococcus hirae copper chaperone CopZ delivers copper(I) to the CopY repressor. FEBS Lett 445:27-30. https://doi.org/10 .1016/s0014-5793(99)00091-5.

58. O'Brien H, Alvin JW, Menghani SV, Doorslaer KV, Johnson MDL. 2019 Characterization of consensus operator site for Streptococcus pneumoniae copper repressor, CopY. bioRxiv 676700.

59. Moore CM, Gaballa A, Hui M, Ye RW, Helmann JD. 2005. Genetic and physiological responses of Bacillus subtilis to metal ion stress. Mol Microbiol 57:27-40. https://doi.org/10.1111/j.1365-2958.2005.04642.x.

60. Pontel LB, Scampoli NL, Porwollik S, Checa SK, McClelland M, Soncini FC. 2014. Identification of a Salmonella ancillary copper detoxification mechanism by a comparative analysis of the genome-wide transcriptional response to copper and zinc excess. Microbiology 160:1659-1669. https://doi.org/10.1099/mic.0.080473-0.

61. Foster AW, Pernil R, Patterson CJ, Robinson NJ. 2014. Metal specificity of cyanobacterial nickel-responsive repressor InrS: cells maintain zinc and copper below the detection threshold for InrS. Mol Microbiol 92: 797-812. https://doi.org/10.1111/mmi.12594.

62. Kay L, Hamilton J, Brun NEL. 2016. Mass spectrometry of B. subtilis CopZ: $\mathrm{Cu}$ (i) -binding and interactions with bacillithiol. Metallomics 8:709-719. https://doi.org/10.1039/c6mt00036c.

63. Newton GL, Rawat M, La Clair JJ, Jothivasan VK, Budiarto T, Hamilton CJ, 
Claiborne A, Helmann JD, Fahey RC. 2009. Bacillithiol is an antioxidant thiol produced in Bacilli. Nat Chem Biol 5:625-627. https://doi.org/10 .1038/nchembio.189.

64. Ma Z, Chandrangsu P, Helmann TC, Romsang A, Gaballa A, Helmann JD. 2014. Bacillithiol is a major buffer of the labile zinc pool in Bacillus subtilis. Mol Microbiol 94:756-770. https://doi.org/10.1111/mmi.12794.

65. Chung CY-S, Posimo JM, Lee S, Tsang T, Davis JM, Brady DC, Chang CJ. 2019. Activity-based ratiometric FRET probe reveals oncogene-driven changes in labile copper pools induced by altered glutathione metabolism. Proc Natl Acad Sci U S A 116:18285-18294. https://doi.org/10 $.1073 /$ pnas.1904610116.

66. Speisky H, Gómez M, Carrasco-Pozo C, Pastene E, Lopez-Alarcón C, Olea-Azar C. 2008. Cu(I)-glutathione complex: a potential source of superoxide radicals generation. Bioorg Med Chem 16:6568-6574. https://doi.org/10.1016/j.bmc.2008.05.026.

67. Hiniker A, Collet J-F, Bardwell JCA. 2005. Copper stress causes an in vivo requirement for the Escherichia coli disulfide isomerase DsbC. J Biol Chem 280:33785-33791. https://doi.org/10.1074/jbc.M505742200.

68. Macomber L, Rensing C, Imlay JA. 2007. Intracellular copper does not catalyze the formation of oxidative DNA damage in Escherichia coli. $J$ Bacteriol 189:1616-1626. https://doi.org/10.1128/JB.01357-06.

69. Vaux DL. 2012. Know when your numbers are significant. Nature 492 $180-181$. https://doi.org/10.1038/492180a.
70. Wasserstein RL, Lazar NA. 2016. The ASA statement on p-values: context, process, and purpose. Am Stat 70:129-133. https://doi.org/10.1080/ 00031305.2016.1154108.

71. Breton YL, Mclver KS. 2013. Genetic manipulation of Streptococcus pyogenes (the group A Streptococcus, GAS). Curr Protoc Microbiol 30: 9D.3.1-9D.3.29.

72. Walker MJ, Hollands A, Sanderson-Smith ML, Cole JN, Kirk JK, Henningham A, McArthur JD, Dinkla K, Aziz RK, Kansal RG, Simpson AJ, Buchanan JT, Chhatwal GS, Kotb M, Nizet V. 2007. DNase Sda1 provides selection pressure for a switch to invasive group A streptococcal infection. Nat Med 13:981-985. https://doi.org/10.1038/nm1612.

73. Ong CY, Berking O, Walker MJ, McEwan AG. 2018. New insights into the role of zinc acquisition and zinc tolerance in group A streptococcal infection. Infect Immun 86:e00048-18. https://doi.org/10.1128/ IAI.00048-18.

74. Rahman I, Kode A, Biswas SK. 2006. Assay for quantitative determination of glutathione and glutathione disulfide levels using enzymatic recycling method. Nat Protoc 1:3159-3165. https://doi.org/10 $.1038 /$ nprot.2006.378.

75. Love MI, Huber W, Anders S. 2014. Moderated estimation of fold change and dispersion for RNA-seq data with DESeq2. Genome Biol 15:550. https://doi.org/10.1186/s13059-014-0550-8. 


\section{University Library}

\section{- M M N E R VA A gateway to Melbourne's research publications}

Minerva Access is the Institutional Repository of The University of Melbourne

\section{Author/s:}

Stewart, LJ;Ong, C-LY;Zhang, MM;Brouwer, S;McIntyre, L;Davies, MR;Walker, MJ;McEwan, AG;Waldron, KJ;Djoko, KY

Title:

Role of Glutathione in Buffering Excess Intracellular Copper in Streptococcus pyogenes

Date:

2020-11-01

\section{Citation:}

Stewart, L. J., Ong, C. -L. Y., Zhang, M. M., Brouwer, S., McIntyre, L., Davies, M. R., Walker, M. J., McEwan, A. G., Waldron, K. J. \& Djoko, K. Y. (2020). Role of Glutathione in Buffering Excess Intracellular Copper in Streptococcus pyogenes. MBIO, 11 (6), https:// doi.org/10.1128/mBio.02804-20.

Persistent Link:

http://hdl.handle.net/11343/272236

License:

CC BY 